$2=$

NASA Contractor Report 4113

DOT/FAA/CT-87130

\title{
Three-Dimensional Trajectory \\ Analyses of Two Drop Sizing \\ Instruments: PMS OAP \\ and PMS FSSP
}

Hillyer G. Norment

CONTRACT NAS3-24630

FEBRUARY 1988

(AASA-CR-4113) IHREE-DIAENSICNAI IFAJECICRY AAALYSES CF THG DEOE SIZIAE IHSIGUMENS: LMS

CAE AAD EMS ESSE Final RefCrt latmcipheric

Science Asscciates) \&E $\mathrm{P}$ LSCL 010
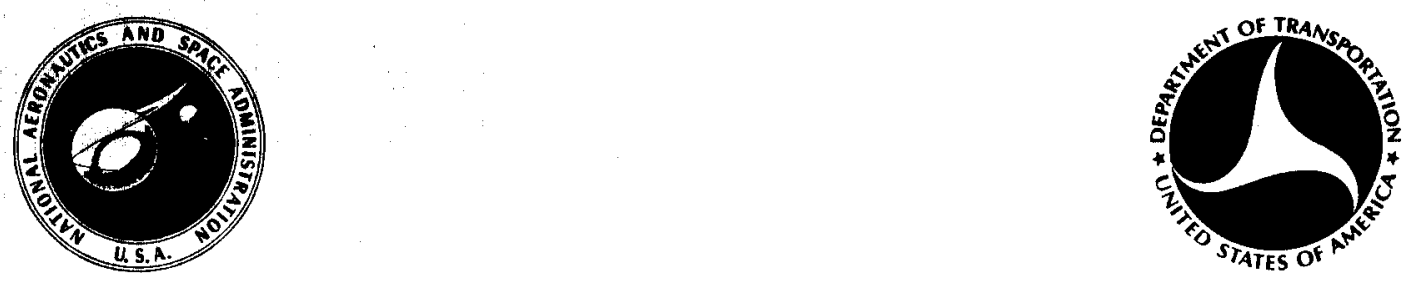
NASA Contractor Report 4113

DOT/FAA/CT-87130

\section{Three-Dimensional Trajectory Analyses of Two Drop Sizing Instruments: PMS OAP and PMS FSSP}

Hillyer G. Norment

Atmospheric Science Associates

Concord, Massachusetts

Prepared for

Lewis Research Center

under Contract NAS3-24630

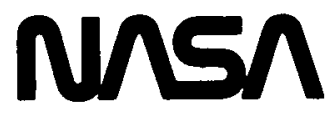

National Aeronautics

and Space Administration

Scientific and Technical

Information Division 
FORWARD

The able assistance of Angela Quealy, Sverdrup Tochnology, Inc., Middleburg Heights, Ohio, with part of the computing and plotting is acknowledged. 
SUMPARY

INTRODUCTION

THE INSTRUMENTS AND AIRPLANE

THE INSTRUMENTS

THE AIRPLANE

Page

MOUNTED INSTRUMENTS

CALCULATION METHODS

FLOW CALCULATION

WATER DROP TRAJECTORY CALCULATION

CONCENTRATION FACTOR

RESULTS

FLIGHT CONDITIONS

FLOW RESULTS

TRAJECTORY RESULTS

OAP

FSSP

Preferred Orientation

CONCLUSIONS

ISOLATED INSTRUMENTS

WING-MOUNTED INSTRUMENTS 51

PREFERRED ORIENTATION 52

APPENDIX A - CONCENTRATION FACTOR AND SPEED RATIO DATA 53

APPENDIX B - DRAG VECTOR ANGLES 
Flow-induced distortions of water drop flux and speed for two hydrometeor measuring instruments, Particle Measuring Systems OAP and FSSP, are predicted by three-dimensional calculations. The instruments are studied in isolation and as mounted under the wing of a DeHavilland Twin Otter airplane. Several free stream air speeds, and angles of attack of $0^{\circ}$ and $4^{\circ}$ are studied for drop diameters ranging from 2 to $1000 \mu \mathrm{m}$.

For the OAP in isolation and under the Twin Otter wing with the airplane at $0^{\circ}$ angle of attack, distortions of practical consequence are not found. At $4^{\circ}$ airplane angle of attack, $17 \%$ undermeasurement of both flux and speed is predicted for cloud-size droplets.

The FSSP presents greater flow obstruction than the OAP, and in addition, air and drops must traverse the measurement tube. As expected, we predict larger flow-induced effects under all circumstances than for the OAP. For the FSSP in isolation and mounted on the Twin Otter at $0^{\circ}$ angle of attack, both speed and flux are predicted to be undermeasured by about $10 \%$ for cloud-size droplets. At $4^{\circ}$ airplane angle of attack, $24 \%$ undermeasurement of both flux and speed is predicted for cloud-size droplets.

For both wing mounted instruments we find that a large portion of the flow induced effects, approximately half, is caused by the instruments themselves. This shows that the common practice of neglecting instrument flow effects in comparison with aircraft flow effects can produce results that are seriously in error.

Preferred orientation (canting) angles of distorted water drops as they pass through the instruments are predicted to vary with drop size, angle of attack and free stream air speed in apparently complicated ways. This needs further study. 


\section{INTRODUCTION}

NASA Lewis Research Center has instrumented a DeHavilland DHC6 Twin Otter airplane (Fig. 1) for use in icing research. Instrumentation (Fig. 2) on the airplane is designed to collect data critical to aircraft icing during traverses through icing clouds. All of these instruments require the sensing or collection of water drops or other hydrometeors, and as is well known (refs. 1,2), flow perturbations caused by the passage of the airplane through the cloud can act to seriously distort the measurements. Since experimental determination of these effects would be prohibitively expensive, three-dimensional flow and hydrometeor trajectory calculation methods (refs. 1, 2, 3) are used for their prediction. The instruments of concern in this study, the PMS* Optical Array Probe (OAP) and PMS* Forward Scattering Spectrometer Probe (FSSP) are numbered 6 and 7 in Figure 2, and are mounted under the Twin 0tter wing as shown in Figures 2, 3 and 4 . Results of similar studies of other instruments shown in Figure 2 are presented elsewhere (ref. 4).

There are two main objectives of this study:

1. Predict distortions of water drop flux and speed caused by flow about the isolated instruments.

2. Predict distortions of vater drop flux and speed caused by flow about complete assemblies of the instruments, their mounts and the Twin Otter airplane.

Results are reported for water drops in the diameter range 2 to $1000 \mu \mathrm{m}$ and for orientations of $0^{\circ}$ and $4^{\circ}$ angles of attack to free stream flows at several speeds. Also, results are compared with similar studies done by the Canadian National Aeronautical Establishment for their Twin otter which is similarly instrumented (refs. 5,6).

* Particle Measuring Systems, Inc., Boulder, Colorado. 
ORIGINAL PAGE IS

OE ROOR QUALITY.

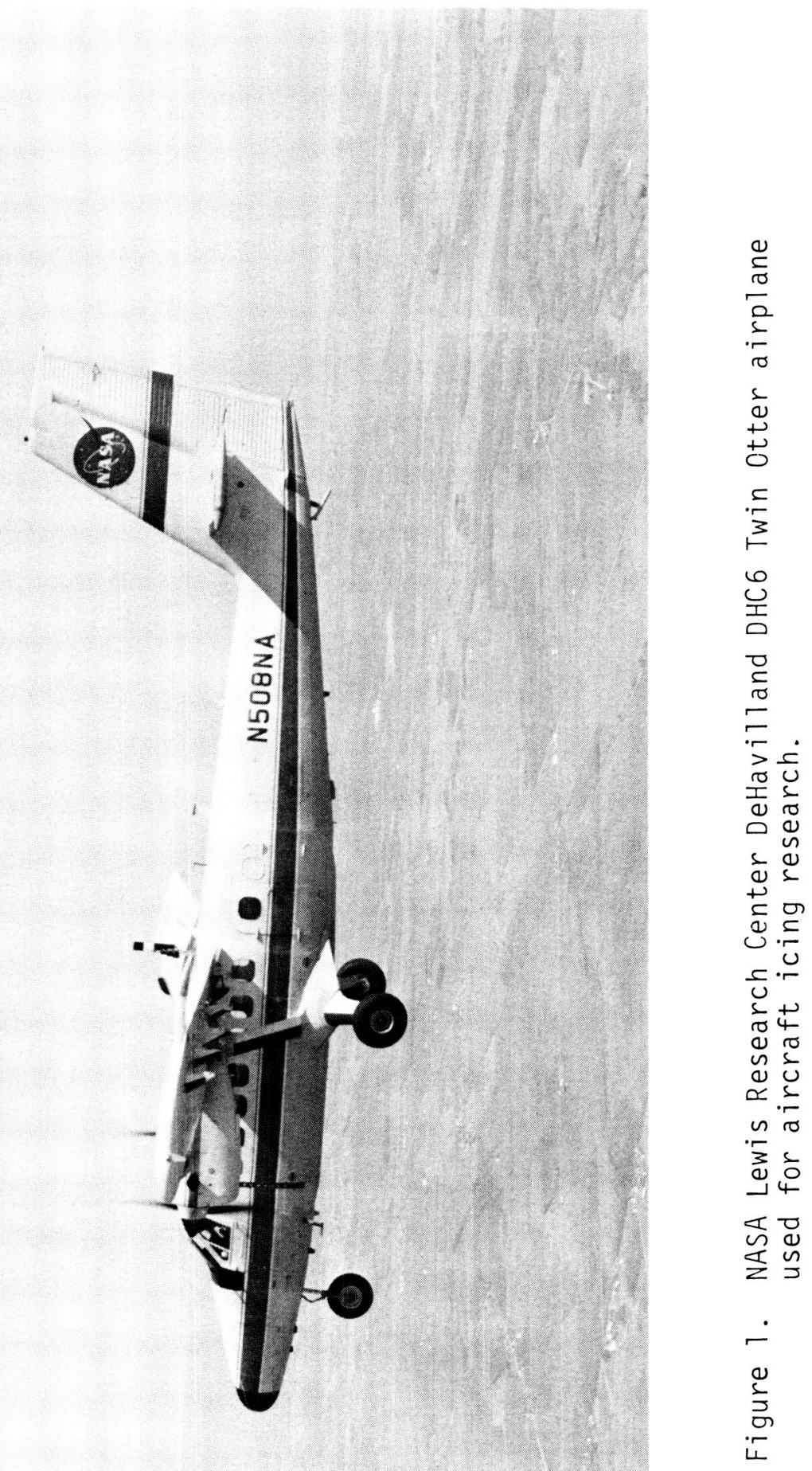




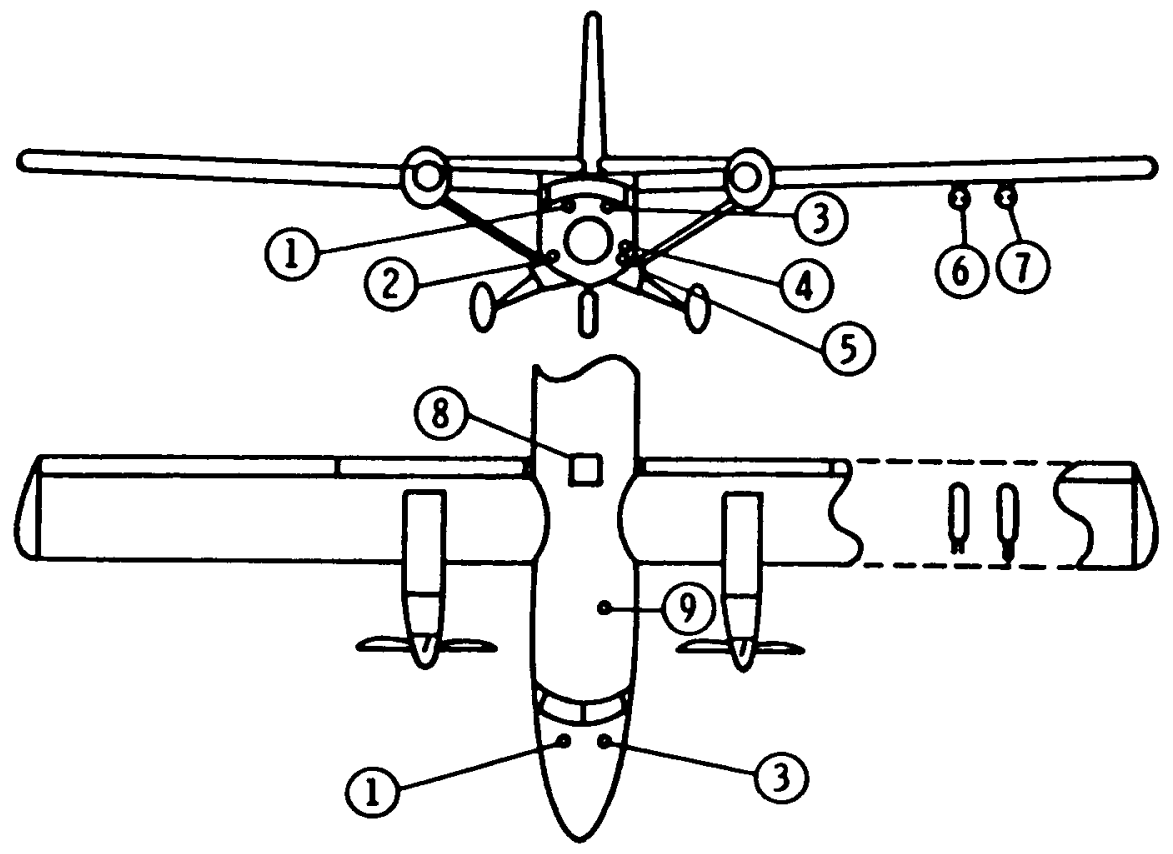

1. Leigh Ice Detector

2. Pressure Ice Rate and Accretion Sensor (PIRAM)

3. Rosemount Ice Detector

4. J-W Liquid Water Content Sensor

5. CSIRO-King Liquid Water Content Sensor

6. OAP Laser Spectrometer

7. FSSP Laser Spectrometer

8. Experiment Carrier Port (Rotating Multi Cylinders)

9. Soot Slide Droplet Sampler

Figure 2. Mount sites of icing instruments on the NASA LeRC Twin Otter. Instruments considered here are numbered 6 and 7 . Results of similar studies of the other instruments are described by Shaw, et al. (ref. 4). 
ORIGINAL PAGE IS

DE POOR QUALITY

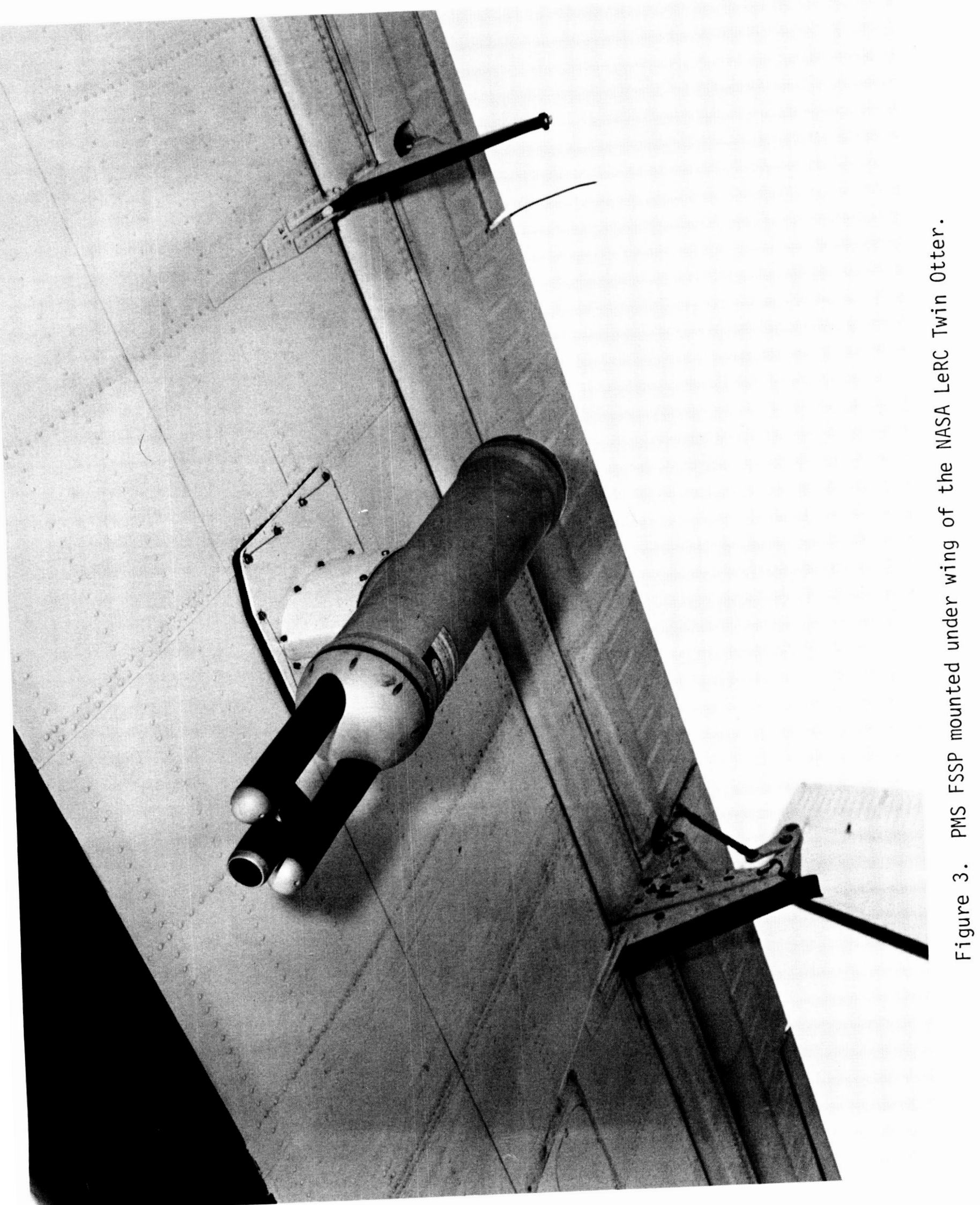




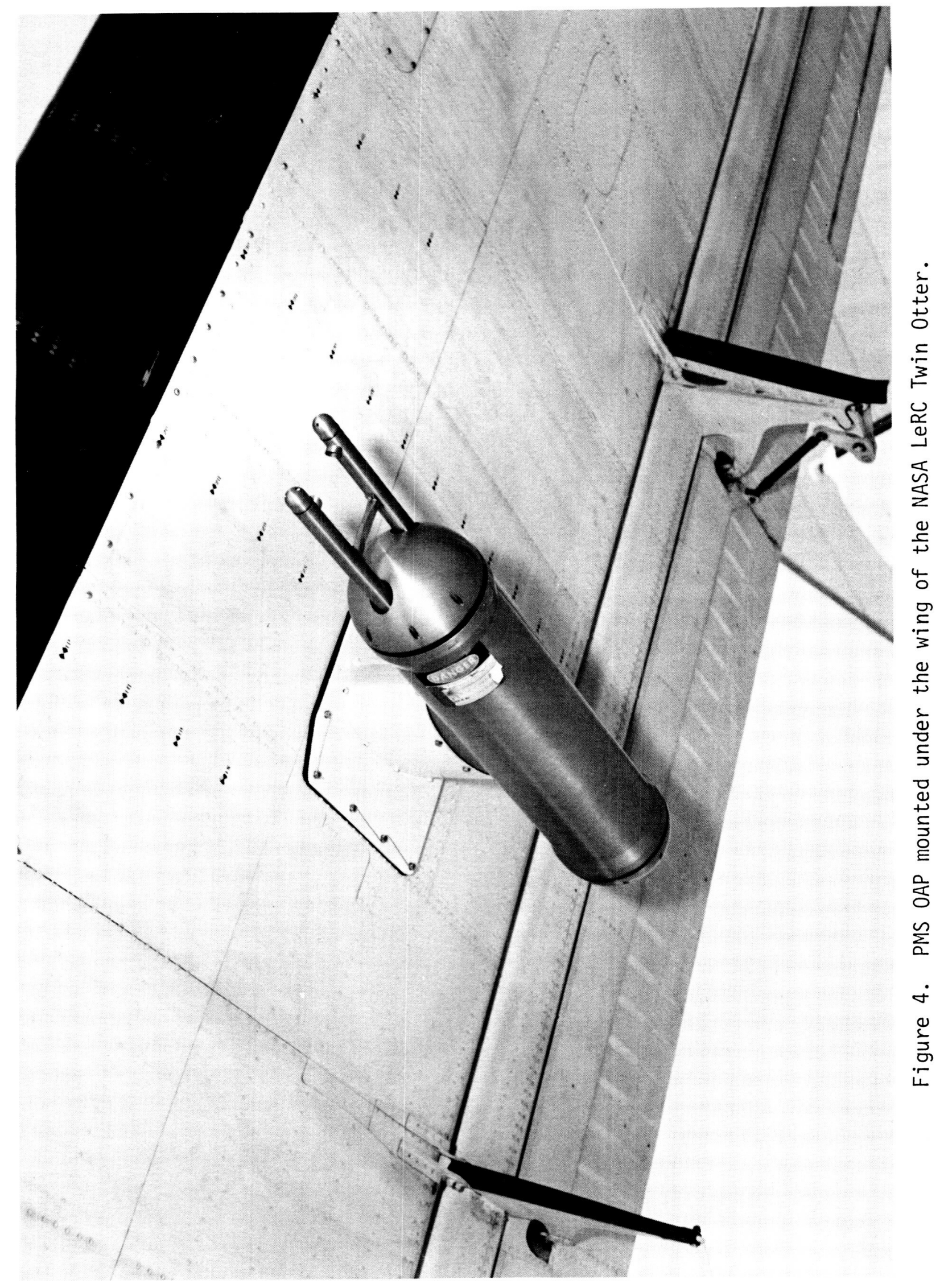

ORIGINAL PAGE IS

OE POOR QUALITY 
Only effects of flow perturbations on drop trajectories are considered. Measurement and sampling errors, and biases caused by optical problems or other workings of the instruments are not addressed. 


\section{THE INSTRUMENTS}

Figures 5 and 6 show computer plots of detailed digital descriptions of the instruments' surfaces suitable for use by the flow calculation codes. Dimensional data also are given in the figures.

The optical array probe (OAP) (refs. 7,8) consists of a cylindrical canister with hemispherical ends, one of which supports a pair of probe arms. A laser beam passes between the probe arms as shown in Figure 5 , and hydrometeors that pass through the beam are sensed and sized. Twodimensional images of the hydrometeors are recorded via use of a linear array of sensors, and to assure that undistorted images are obtained, transit speeds of the hydrometeors through the beam must be known. Maximum diameter range capability of the instrument is approximately 75-2000 $\mu \mathrm{m}$.

The forward scattering spectrometer probe (FSSP) (ref. 8) uses a canister with hemispherical ends that is identical in size and shape with the one used by the OAP. Support arms, which are considerably larger in diameter than those of the OAP, extend from one end of the canister, and these support a measurement tube through which the particles must pass (Fig. 6). A laser beam passes diametrically across the inside of the measurement tube; particles are sensed as they intersect this beam and are sized by use of Mie scattering theory. Maximum diameter range capability is approximately 2-100 $\mu \mathrm{m}$.

Structural details of portions of the instruments that are located well aft of the sampling volumes contribute little of significance to flow at and forward of the sampling volumes, so that an abbreviated version of the canister was used for studies of the instruments in isolation. Figure 7 shows computer plots of the instruments with the abbreviated canister as used for the isolated instruments studies. 


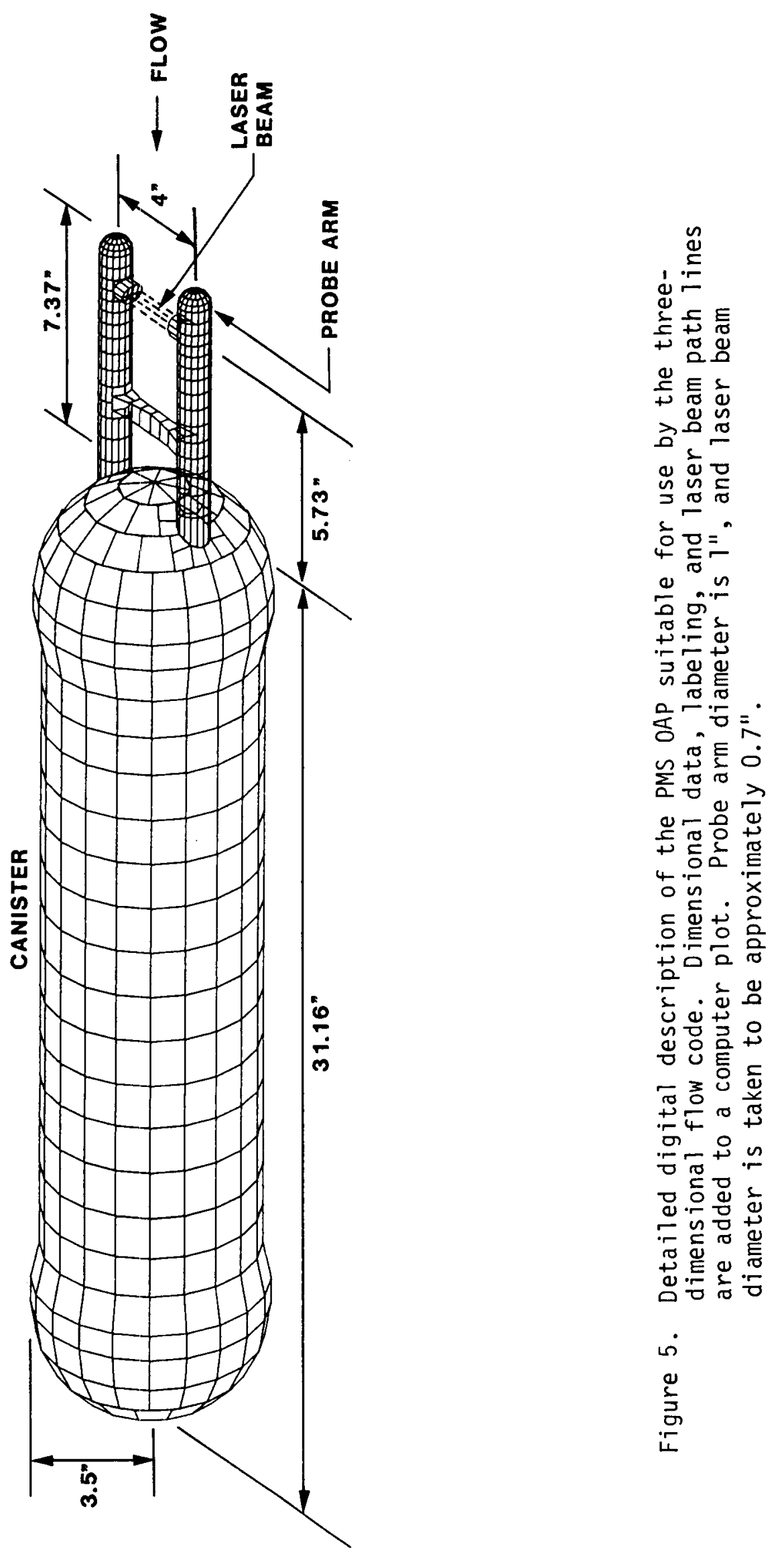



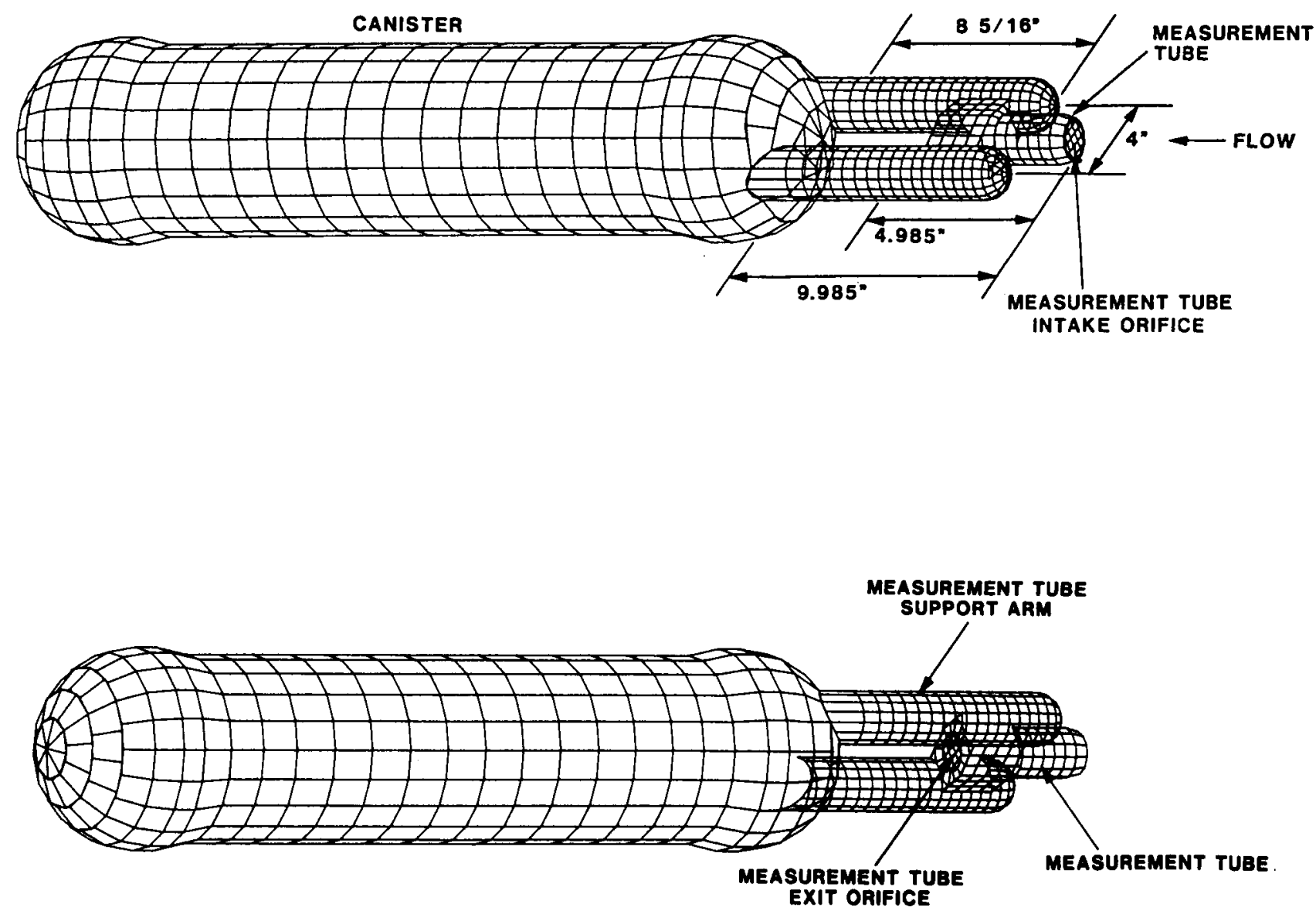

Figure 6. Detailed digital description of the PMS FSSP suitable for use by the three-dimensional flow code. Dimensional data and labeling are added to a computer plot. Inside diameter of the measurement tube is $15 / 16^{\prime \prime}$. Support arm diameter is $17 / 8 "$. 


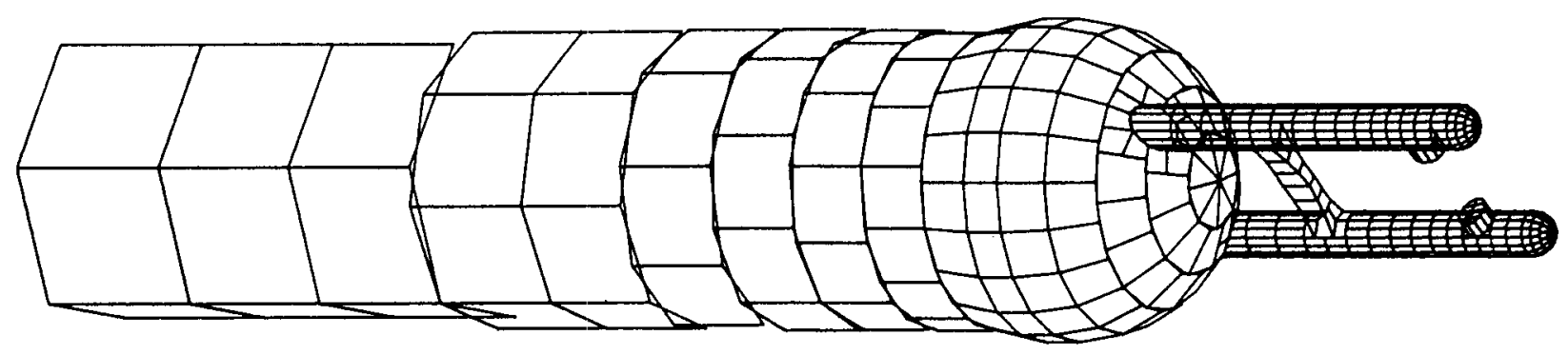

a. PMS OAP

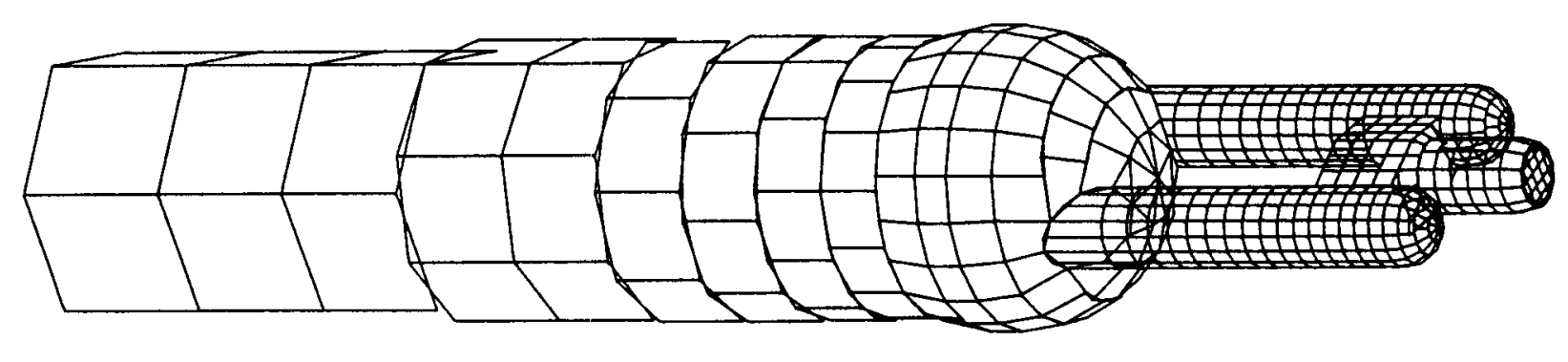

b. PMS FSSP

Figure 7. Digital descriptions of the PMS OAP and FSSP used for studies of the instruments in isolation. Aft ends of the cannisters are abbreviated; otherwise the paneling is the same as shown in Figs. 5 and 6. 


\section{THE AIRPLANE}

A detailed digital description of the Twin Otter airplane has been prepared that includes al1 major components (Fig. 8). For this study this much detail is not needed, so that an abbreviated version of the paneling was used as shown in Figure 9. Since neglect of the engine nacelle might be questionable, concentration factor (defined below) calculations were done with the nacelle included for water drops to the OAP, which instrument is closest to the nacelle. Comparisons of these results with results obtained without the nacelle show unambiguously that the nacelle does not significantly influence the results.

The wing airfoil section, NACA 0016, is spanwise uniform with a constant 78" chord. The wing has no geometric twist. To mount the wing on the fuselage the following operations are required:

1. Rotation by $2.5^{\circ}$ about a spanwise axis, leading edge upward.

2. Dihedral rotation by $3^{\circ}$ about a chordwise axis at a distance of $35.15^{\prime \prime}$ from the symmetry plane, tip upward relative to root.

\section{MOUNTED INSTRUMENTS}

Figure 10 shows computer plots of the instrument canister and wing mounts. The aft portion of the canister is simplified slightly compared with the detailed version shown in Figs. 5 and 6 . The wing paneling is designed such that the mount plates (Fig. 10a) exactly cover two panels (i.e., the blackened panels in Fig. 9b).

Figure 11 shows the instruments mounted under the Twin Otter wing. The instruments' axes make angles of 50 with the wing cherd plane, forward end down. However, as mounted on the fuselage, the wing chord plane is tilted upward by $2.5^{\circ}$ relative to the fuselage axis, so that the instruments' axes have a net downward tilt of $2.5^{\circ}$ relative to the fuselage axis. 


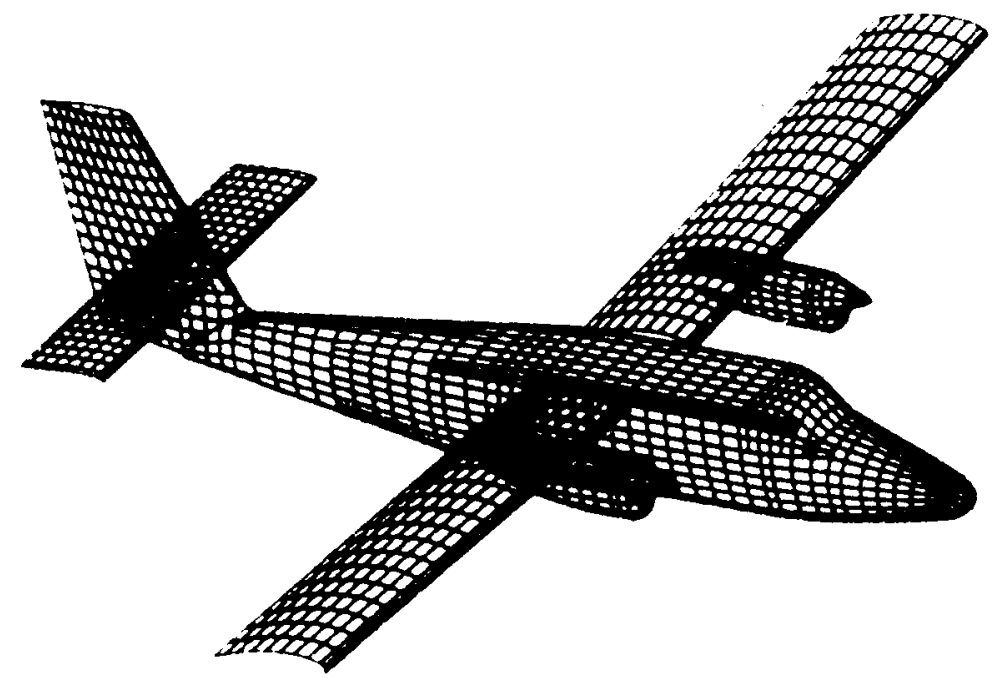

Figure 8. Digital description of the complete Twin 0tter airplane suitable for use by the three-dimensional flow code. 


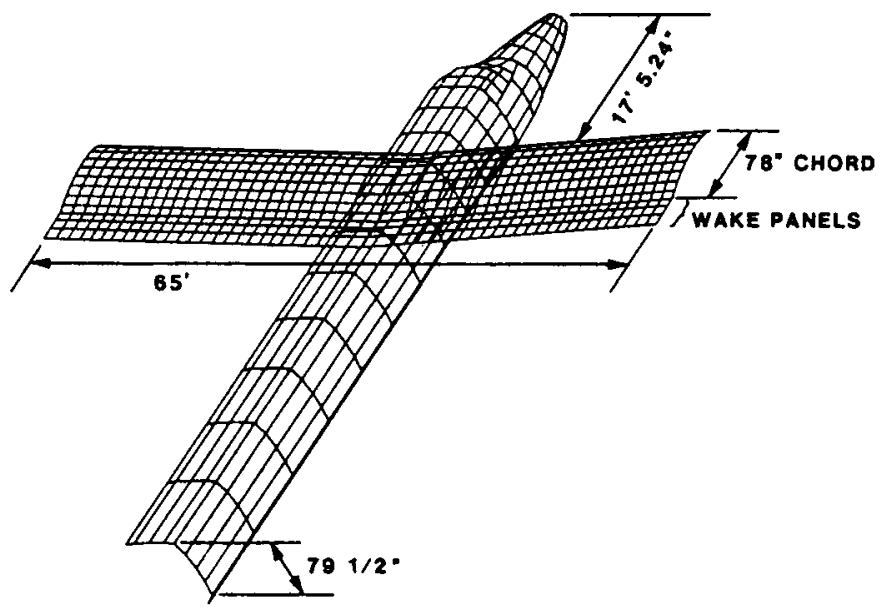

a. Perspective view

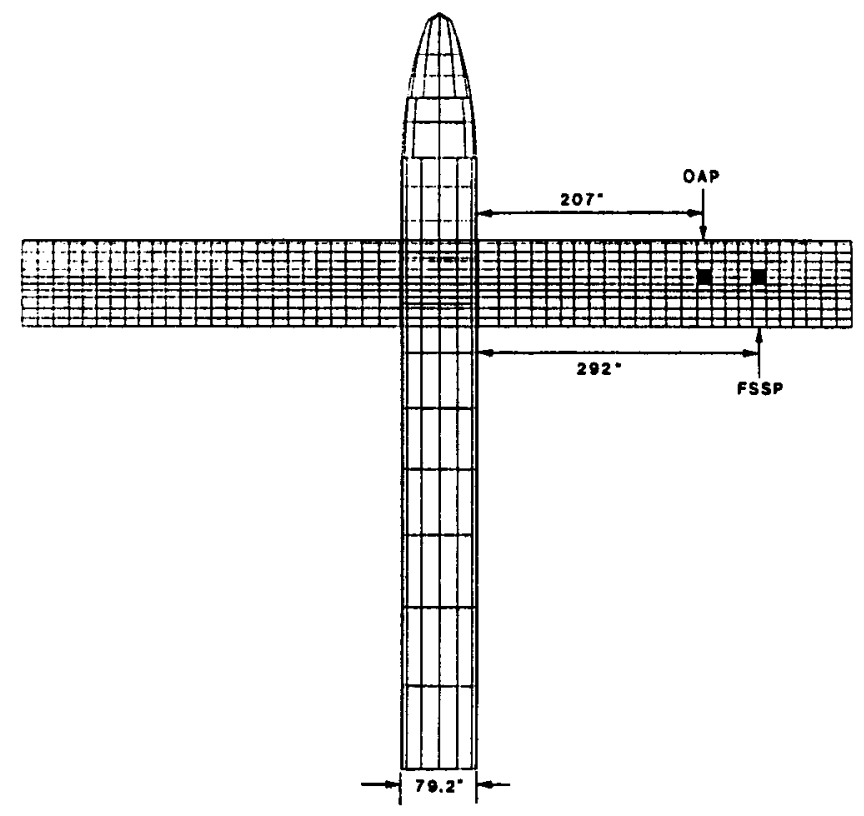

b. View of underside

Figure 9. Digital description of the Twin Otter used for this study. Panels covered by the instrument mount plates (Fig. 10) are blackened. Dimensional data and labeling are added to a computer plot. 


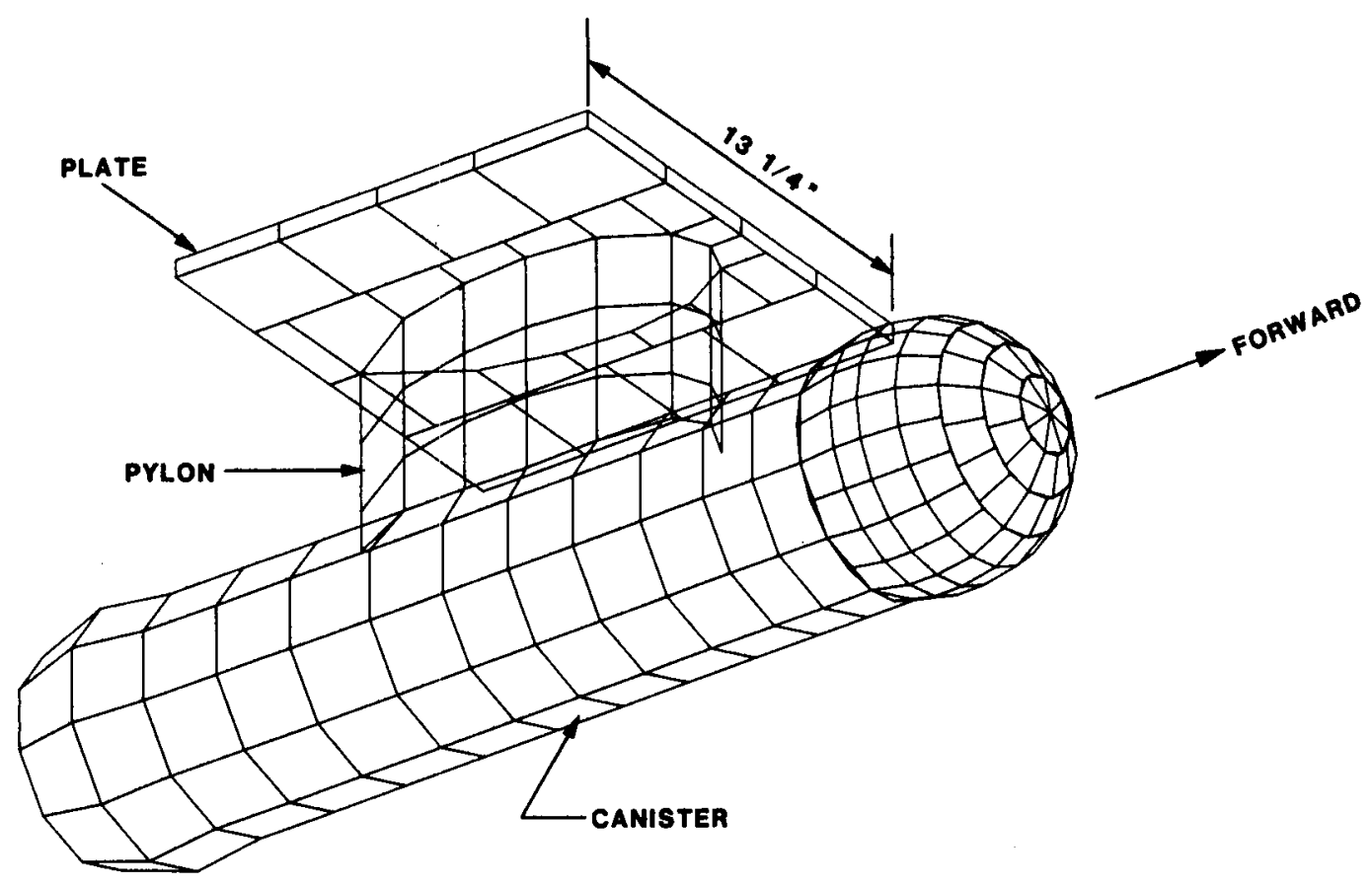

a. Perspective view

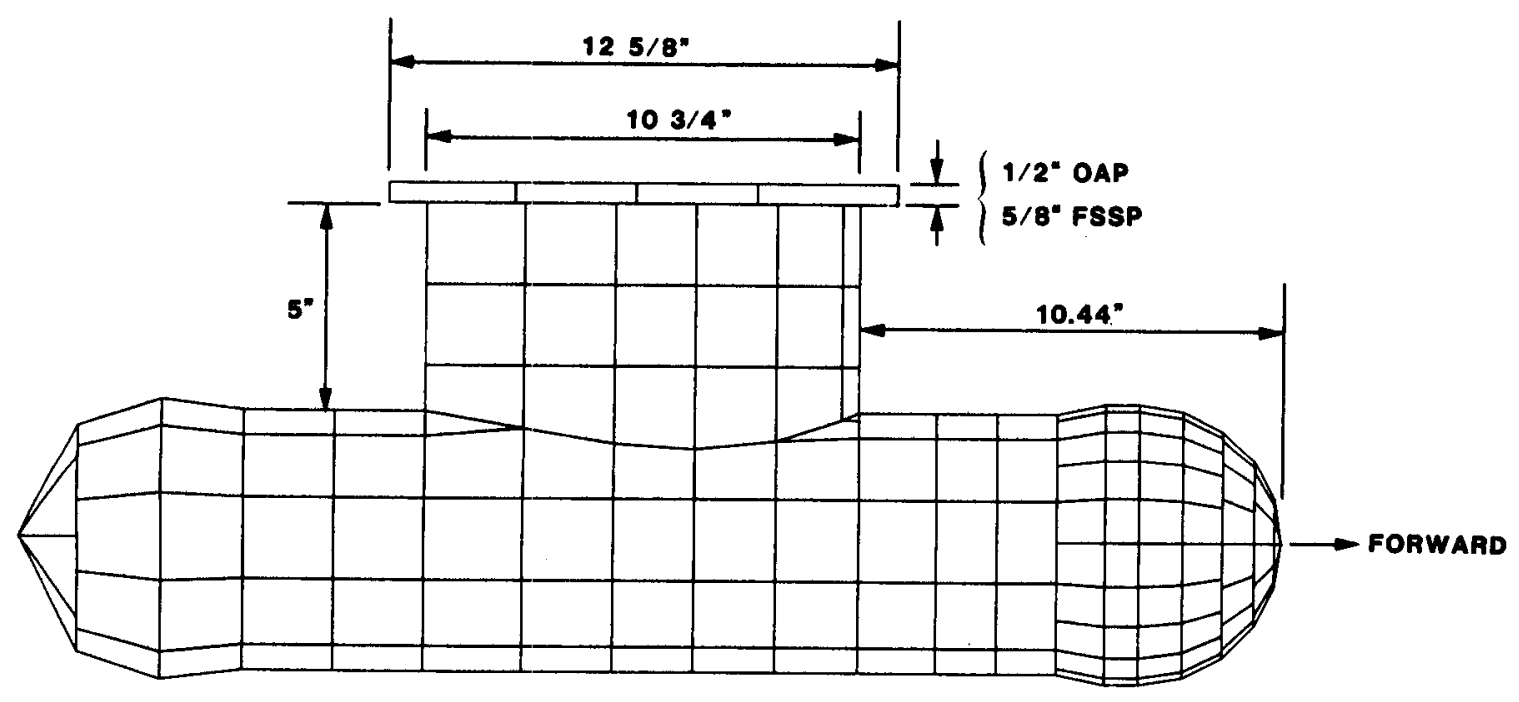

b. Side view

Figure 10. Digital description of the PMS canister and its mounts used for studies of the wing-mounted instruments. 


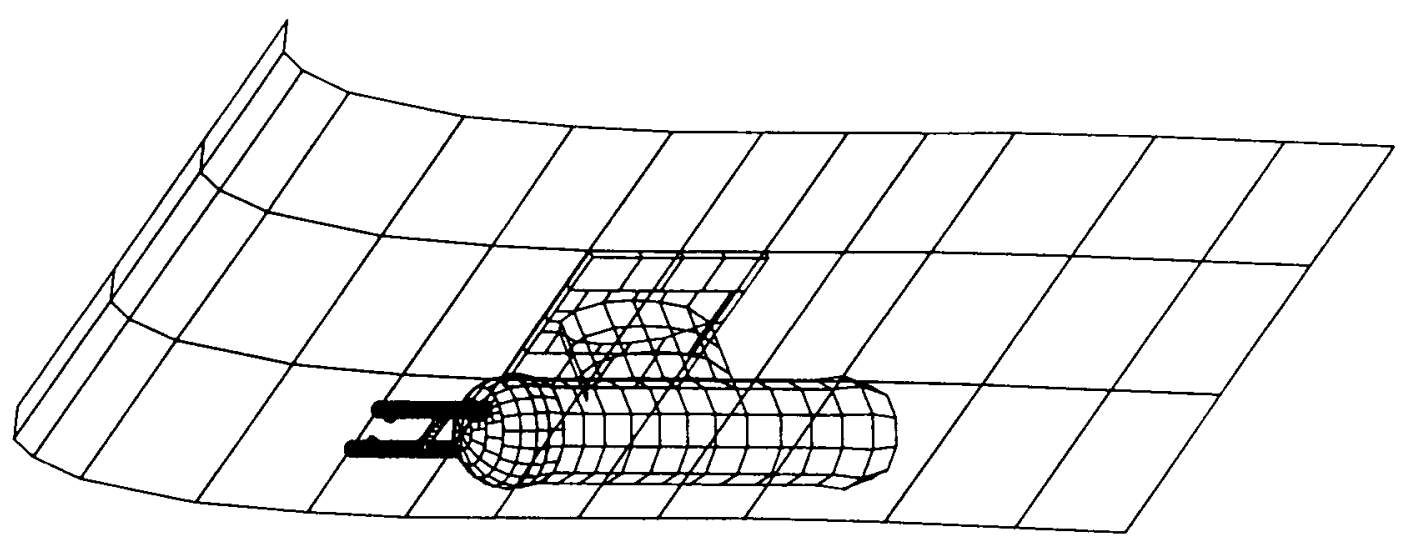

a. PMS OAP

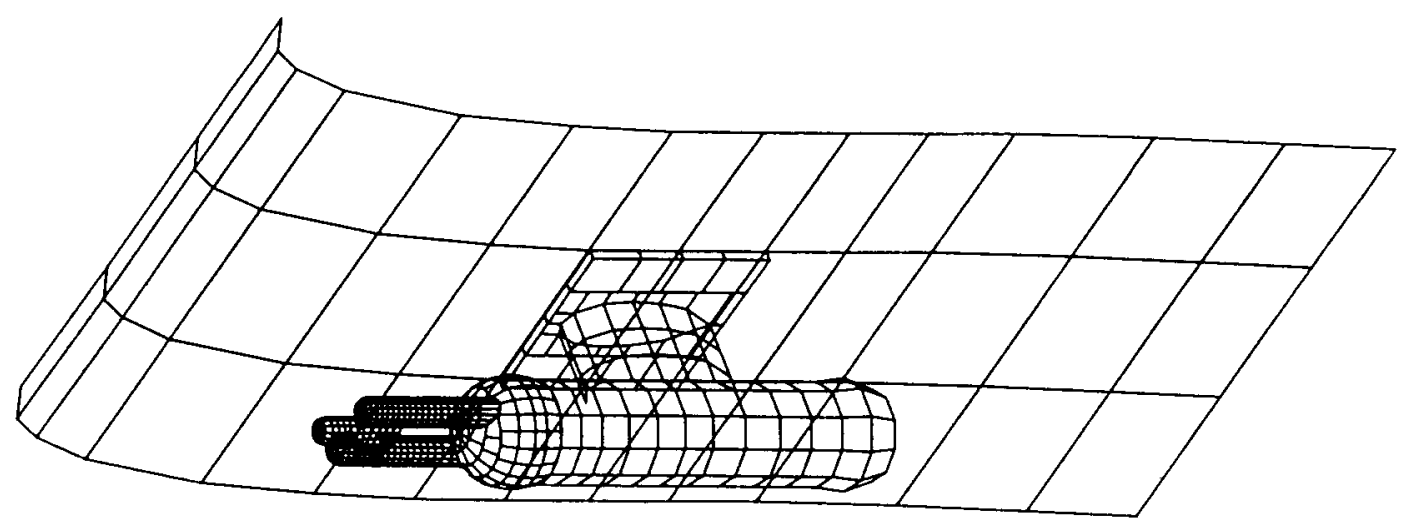

b. PMS FSSP

Figure 11. Computer plots of the wing-mounted instruments including short segments of the wing. Only the under side of the wing surfaces are plotted to avoid confusion of overlapping lines. 
CALCULATION METHODS

\section{FLOW CALCLLATION}

Air flow about the exterior of a three-dimensional body of arbitrary shape is calculated by a modified version of a first order panel code developed by Hess (refs. 3, 9). The body surface must be approximated by contiguous, plane quadrilateral panels as illustrated by Figures 5-11 above. Details of the method are given in references 3 and 9, and applications are discuswed in references 1 and 2 .

With regard to accuracy, Hess (ref. 9) and Hess and Smith (ref. 10) report results of a large number of validation studies for flow about both lifting and nonlifting bodies. Panel code results are compared with exact results calculated from theory for simple bodies, and with experimental data for complicated bodies and combinations of bodies (e.g., wing-fuselage combinations). These comparisons show that the panel code accurately predicts subsonic (i.e., essentially incompressible) exterior flows. On the other hand it is not capable of accurately predicting interior flows through tubes and ducts, and therefore cannot be used to predict air flux through the FSSP measurement tube.

Air and hydrometeors must pass through the FSSP measurement tube, inside of which the hydrometeors are sized by Mie scattering theory. The first order panel flow code discussed above can accommodate flow in/out of an orifice, providing flux in/out of the orifice is specified, but as noted it cannot accurately predict flow through the tube. A second order panel flow code is required to accurately simulate interior flows. Since a second order three-dimensional panel code was not readily available, some means was needed to estimate air flux through the FSSP measurement tube, which then could be input to the first order code.

An axisymmetric, second order pane 1 code (refs. 11,12) was used to calculate flow through the measurement tube for the measurement tubecanister combination of the isolated instrument; the measurement tube support arms (Fig. 6b) and airplane could not be included because of the 
requirement that the body have axial symmetry. Average air flux into the orifice, which does not vary appreciably between $0^{\circ}$ and $4^{\circ}$ angles of attack, was calculated to be $95.9 \%$ of the free stream flux. To estimate the effect of the support arms on the flow, a three-dimensional calculation for the canister-support arms combination, with the measurement tube omitted, and an axisymmetric calculation for the cannister alone were done. The difference in flow between these calculations at the intake orifice location was $3.9 \%$ of the free stream flux, which again did not vary appreciably between $0^{\circ}$ and $4^{\circ}$ angles of attack. The net flux into the orifice, accounting approximately for the effect of the support arms, is thus approximately $92 \%$ of the free stream flux.

The three-dimensional first order code requires that the intake and exit orifices be paneled as though they are impervious surfaces and Figure 12 shows the paneling used: each orifice is represented by twenty-one panels. The flux through each orifice panel is specified in the input. For the FSSP in isolation, as well as when mounted under the Twin 0tter wing with the airplane at $0^{\circ}$ angle of attack, this specification was taken to be $92 \%$ of the free stream flux as discussed above. However, calculation with the airplane at $4^{\circ}$ angle of attack without the instrument shows an air flux at the location of the FSSP orifice of $89 \%$ of the free stream value (owing to partial stagnation under the wing). Accordingly, with the airplane at $4^{\circ}$ angle of attack, the flux through each panel was taken to be $82 \%$ ( $92 \times .89$ ) of the free stream flux.

\section{WATER DROP TRAJECTORY CALCULATION}

Assuming that the bulk air flow is not perturbed by the particles, and ignoring air density compared with water density, we use three dimensional, dimensionless equations of motion for water drops

$$
\frac{d \vec{v}_{p}}{d \tau}=\frac{1}{N_{F}}\left[\frac{1}{v_{s}}\left(\vec{v}_{a}-\vec{v}_{p}\right) \frac{N_{D} N_{R, s}}{N_{D, s} N_{R}}-\vec{k}\right]
$$



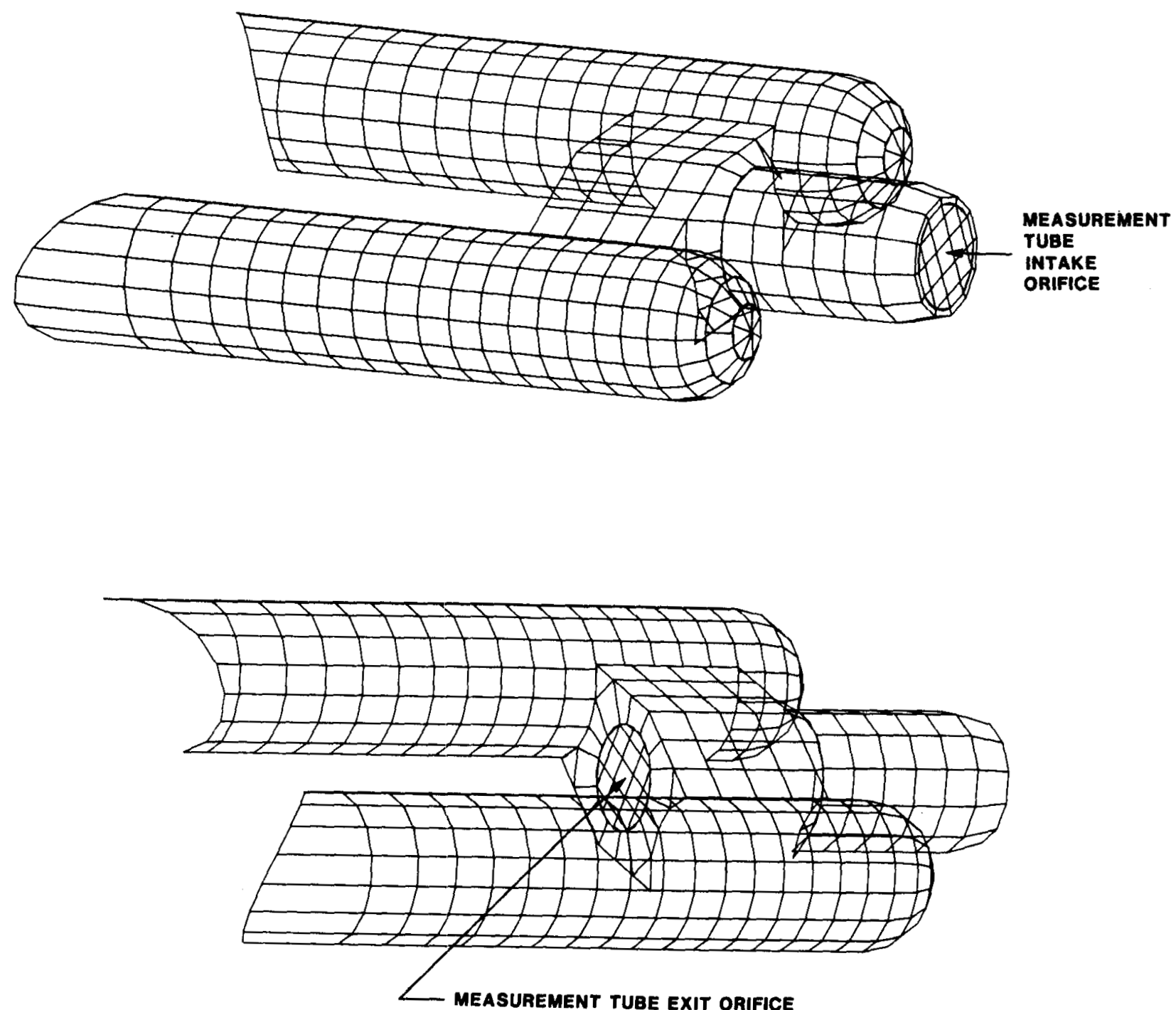

Figure 12. Computer plots of the PMS FSSP measurement tube and its support arms. Intake and exit orifices of the measurement tube are each represented by 21 panels. (See Fig. 6 for dimensional data.) 
Non-dimensional quantities are:

$\begin{array}{ll}\vec{v}_{p}, \vec{v}_{d} & \begin{array}{l}\text { drop and air velocities } \\ v_{S}\end{array} \\ \begin{array}{l}\text { still-air, terminal settling speed of the } \\ \text { drop } \\ \vec{k}\end{array} & \begin{array}{l}\text { unit vector in the } z \text { (upward) direction } \\ \text { time }\end{array} \\ N_{D}=C_{D} N_{R}^{2} & \text { Davies number } \\ N_{F}=v^{2} /(L g) & \text { Froude number } \\ N_{R}=\frac{\rho \delta}{n}\left|\vec{v}_{a}-\vec{v}_{p}\right| v & \text { Reynolds number } \\ C_{D} & \text { water drop drag coefficient }\end{array}$

Dimensional quantities are:

$\begin{array}{ll}\delta & \text { equivalent sphere drop diameter } \\ \rho & \text { air density } \\ \mathrm{n} & \text { air viscosity } \\ \mathrm{g} & \text { gravity acceleration constant } \\ V_{\infty} & \text { free stream airspeed } \\ \mathrm{L} & \text { a characteristic dimension of the body }\end{array}$

Here length is normalized by dividing by $L$, velocity by $V_{\infty}$ and time by $L / N_{\infty} \cdot N_{D, S}$ and $N_{R, S}$ are for still-air, terminal drop settling (ref. 13).

We initiate the calculation far enough upstream to be essentially beyond the influence of the body where we can take $\vec{v}_{p}=\vec{v}_{a}-\vec{k} v_{s}$. We compute $N_{R}$ from these data, calculate $N_{D}$ from $N_{R}$ using experimental drag data for water drops (ref. 14), and proceed straightforwardly with a numerical integration of eq. (1) to obtain $\vec{v}_{p}$ and drop coordinates stepby-step from the free stream to the instrument. Air velocity, $\vec{v}_{a}$, is calculated via the flow codes as needed during the integration. Details are given in reference 3 . 
Accuracy of the numerical calculations has been studied in some detail (ref. 15), and trajectory results have been compared with experimental data where possible (refs. 3,16 ). Results of these studies are summarized in reference 2. Comparisons with experimental data are satisfactory, and numerical integration errors are found to be negligible.

\section{CONCENTRATION FACTOR}

To estimate flow-induced drop flux distortions seen by the instruments, we compute a quantity called concentration factor, $C_{F}$, defined as

$$
C_{F}=\frac{\text { water drop flux at the instrument sampling volume }}{\text { water drop flux in the free stream }}
$$

$C_{F}$ is estimated, for water drops of specified size, by computing a flux tube of drops from the unperturbed free stream to the instrument sampling volume. Figure 13 gives a crude illustration of such a flux tube. It is defined by a central trajectory (the dashed line in the figure) surrounded by a specified number* of trajectories that intersect the target $\mathrm{plane}$ approximately at the corners of a small, regular polygon about the center point of the instrument sampling volume. The initial plane is in the unperturbed free stream. These trajectories are computed by an iterative calculation that ensures that they intersect the target plane within a preset error tolerance of the desired target points.*

Since the particle mass transfer rate through the tube is constant at all cross sections, it is easily shown that

$$
C_{F} \simeq \frac{A}{A_{t}},
$$

where $A$ and $A_{t}$ are the flux tube cross sectional areas in the initial and target planes.

*A sensitivity study (ref. 15) has shown that six flux tube boundary trajectories and a target point error tolerance of $25 \%$ of the target circle radius are quite adequate for concentration factor calculations. Accordingly we have used these parameter settings (NW $=6, \mathrm{TOL}=0.25$; ref. 3, p. 84) for this study. 


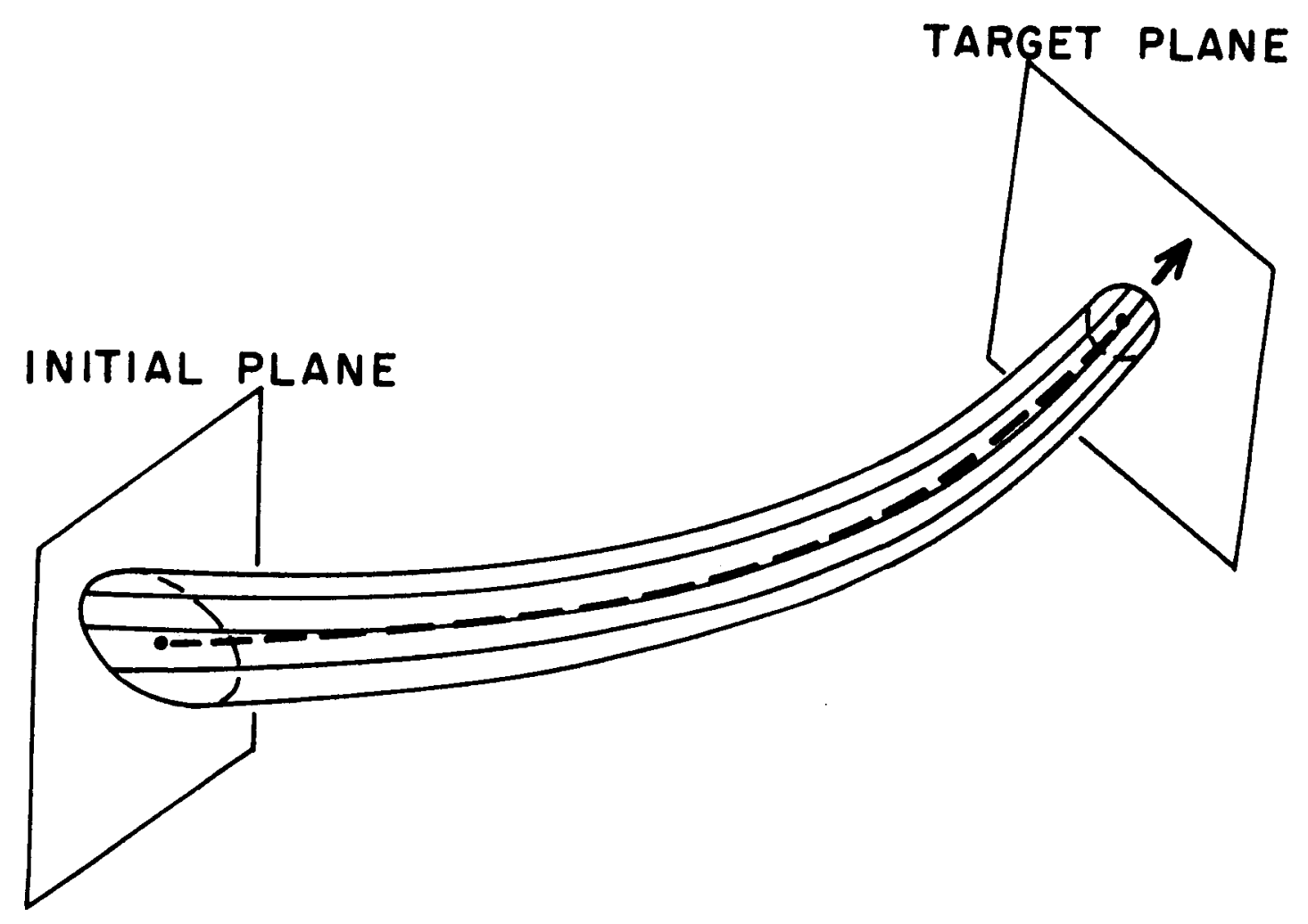

Figure 13. Artist's rendition of a water drop flux tube. The initial plane is normal to the central trajectory (dashed line), as is the target plane for the OAP. For the FSSP, the target plane is parallel to the measurement tube orifice plane. The initial plane is upstream in the unperturbed free stream. 
For the OAP the flux tube center point in the target plane is at the center point of the laser beam (Fig. 5), and the flux tube boundary target points lie on a circle about the center point with a radius approximately equal to that of the laser beam. For the FSSP, the target plane is constrained to be parallel to that of the measurement tube orifice, and to lie a distance of 0.05 " upstream of the orifice. Thus, the center of the flux tube in the target plane lies on the axis that passes through the center of the measurement tube, but lies a distance 0.05 " upstream of the orifice center.

For the FSSP calculations were done for two target circle radii: 1. a radius siightly less $(0.008$ " less) than the measurement tube inside radius $\left(21 / 32^{\prime \prime}\right)$, and 2 . a radius one half of the measurement tube inside radius. The coarser flux tubes are used to assess overall collection efficiency of the tube, while the finer flux tubes are used to assess collection efficiency for those droplets that are more likely to be accurately sensed and sized by the instrument.

Trajectories of large drops are initiated at a distance of at least 795" (10 fuselage diameters) upstream of the target planes. It is found that this distance is not always large enough for small droplets, particularly for the wing-mounted FSSP at nonzero angle of attack, so this distance is doubled for droplets of diameters $20 \mu \mathrm{m}$ and less. 
RESULTS

\section{FLIGHT CONDITIONS}

Since potential flow is calculated, the flow fields are independent of atmospheric properties and air speed, but trajectory calculations are dependent on these conditions. Usually the dependences are weak, but some dependence on air speed is found in this case, particularly for the FSSP. As expected, angle-of-attack is important for the wing-mounted instruments.

Al1 calculations are done for two angles of attack: $0^{\circ}$ and $4^{\circ}$ (forward end up) relative to the free stream direction (which direction is always normal to the gravity vector). In the case of an isolated instrument the angle is between the instrument axis and the free stream direction, while for an airplane-mounted instrument the angle is between the airplane fuselage axis and the free stream direction. Instrument axis angles of attack for the mounted instruments are discussed in the next section.

Atmospheric properties are those at $7 \mathrm{kft}$ in the U.S. Standard Atmosphere (ref. 17). Specifically, air density is $0.993 \mathrm{~kg} \mathrm{~m}^{-3}$ and temperature is $274.3^{\circ} \mathrm{K}$. All calculations are done at two free stream air speeds: 95 and $250 \mathrm{kts}$ for the isolated instruments, and 95 and $130 \mathrm{kts}$ for the airplane-mounted instruments.

\section{FLOW RESULTS}

Figure 14 shows the flow field for the PMS OAP mounted under the Twin Otter wing with the airplane at $0^{\circ}$ angle of attack. Since the instrument axis makes a $5^{\circ}$ angle (forward end down) with the wing chord plane, and the chord plane makes a $2.5^{\circ}$ angle (leading edge up) with the fuselage axis, the instrument axis makes a net $2.5^{\circ}$ angle (forward end down) with the free stream flow vector when the airplane is at $0^{\circ}$ angle of attack. (For the $4^{\circ}$ airplane angle of attack, the instrument axis makes a net $1.5^{\circ}$ angle (forward end up) with the free stream flow vector.) Flow vectors at the center of the laser beam (shown with a circled root in Figure 14) have the following properties: 


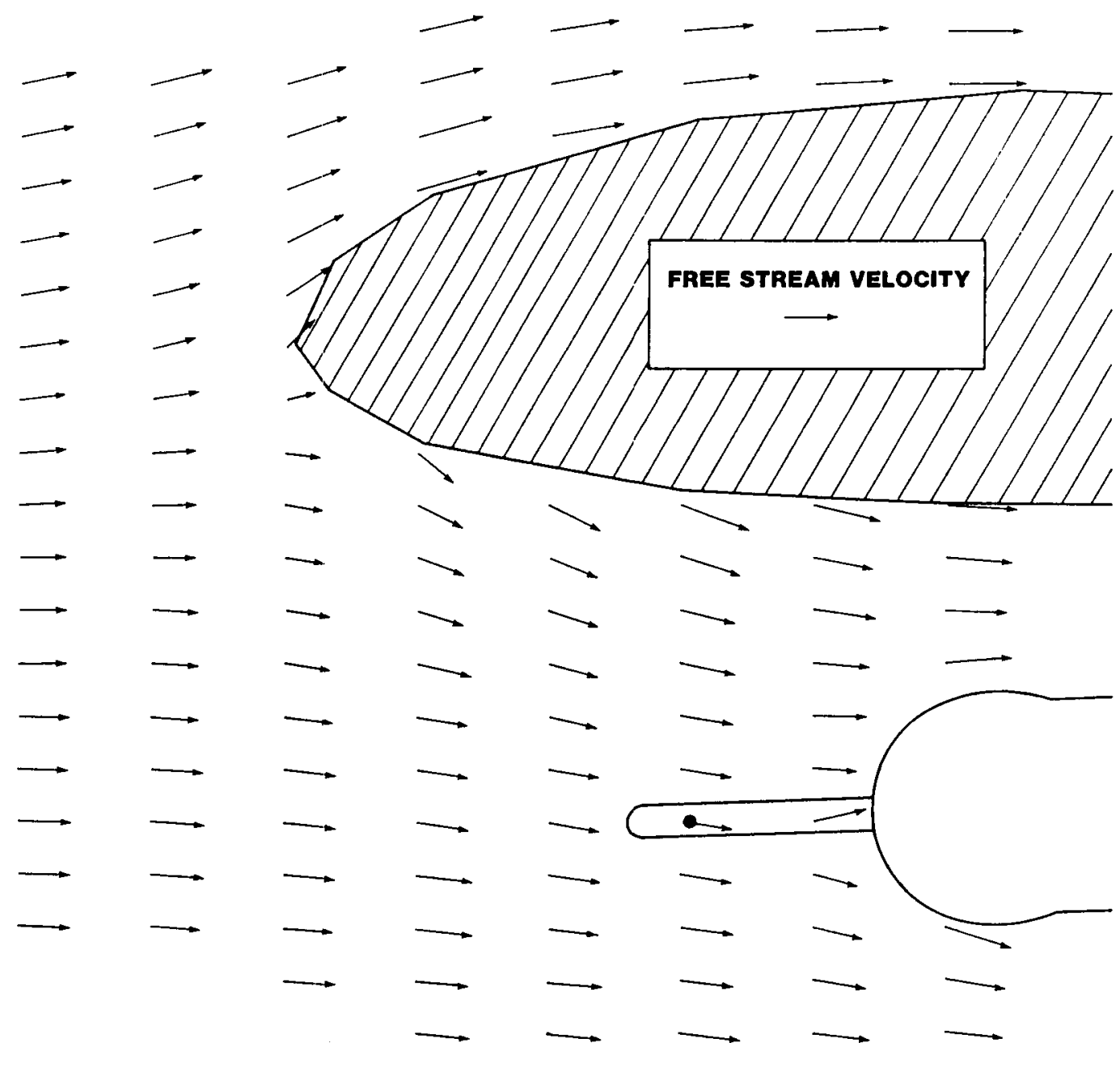

Figure 14. Flow field in the vertical plane normal to the OAP laser beam and through its center $(\bullet)$. The airplane fuselage axis is at 00 angle of attack to the free stream flow. 


\begin{tabular}{|c|c|c|c|}
\hline $\begin{array}{l}\text { Airplane } \\
\text { Angle of } \\
\text { Attack }\end{array}$ & $\begin{array}{l}\text { Magnitude } \\
\text { Relative to } \\
\text { Free Stream } \\
\end{array}$ & $\begin{array}{c}\text { Angle Relative } \\
\text { to Horizontal } \\
\text { Plane* } \\
\end{array}$ & $\begin{array}{l}\text { Angle Relative } \\
\text { to the Airplane } \\
\text { Symmetry Plane }\end{array}$ \\
\hline $0^{\circ}$ & $96.4 \%$ & $-9.2^{\circ}$ & $1.1^{\circ}$ \\
\hline $4^{\circ}$ & $83.1 \%$ & -8.90 & $1.8^{\circ}$ \\
\hline
\end{tabular}

The center of the laser beam is approximately 10" from the wing surface.

Figure 15 shows the flow field for the PMS FSSP mounted under the Twin Otter wing with the airplane at $0^{\circ}$ angle of attack. Net instrument axis angles relative to the free stream vector for airplane angles of attack of $0^{\circ}$ and $4^{\circ}$ are the same as for the OAP. Figure 16 shows flow into the measurement tube orifice, again for an airplane angle of attack of $0^{\circ}$. Flow vectors at the center of the orifice have the following properties:

\begin{tabular}{cccc}
$\begin{array}{c}\text { Airplane } \\
\text { Angle of } \\
\text { Attack }\end{array}$ & $\begin{array}{c}\text { Magnitude } \\
\text { Relative to } \\
\text { Free Stream }\end{array}$ & $\begin{array}{c}\text { Angle Relative } \\
\text { to Horizontal } \\
\text { Plane* }\end{array}$ & $\begin{array}{c}\text { Angle Relative } \\
\text { to the Airplane } \\
\text { Symmetry Plane }\end{array}$ \\
\cline { 2 - 3 } & $89.9 \%$ & $-12.7^{\circ}$ & Sy \\
$4^{\circ}$ & $76.7 \%$ & $-9.7^{\circ}$ & 3.10
\end{tabular}

The center of the orifice is approximately $11^{\prime \prime}$ from the wing surface.

\section{TRAJECTORY RESULTS}

We are interested in two quantities: 1. concentration factor (eqs. (2) and (3)) and 2. drop speed ratio, $v_{p}$ (eq. (1)). Deviation of concentration factor from unity expresses distortion in drop flux seen by the instrument. This distortion is caused by interaction of the drops with flow perturbations caused by passage of the airplane and instruments through the air. Instrument induced measurement biases are not considered here.

*The horizontal plane is normal to the gravity vector.

+These angles are such as to tilt the vectors to the outboard direction. 


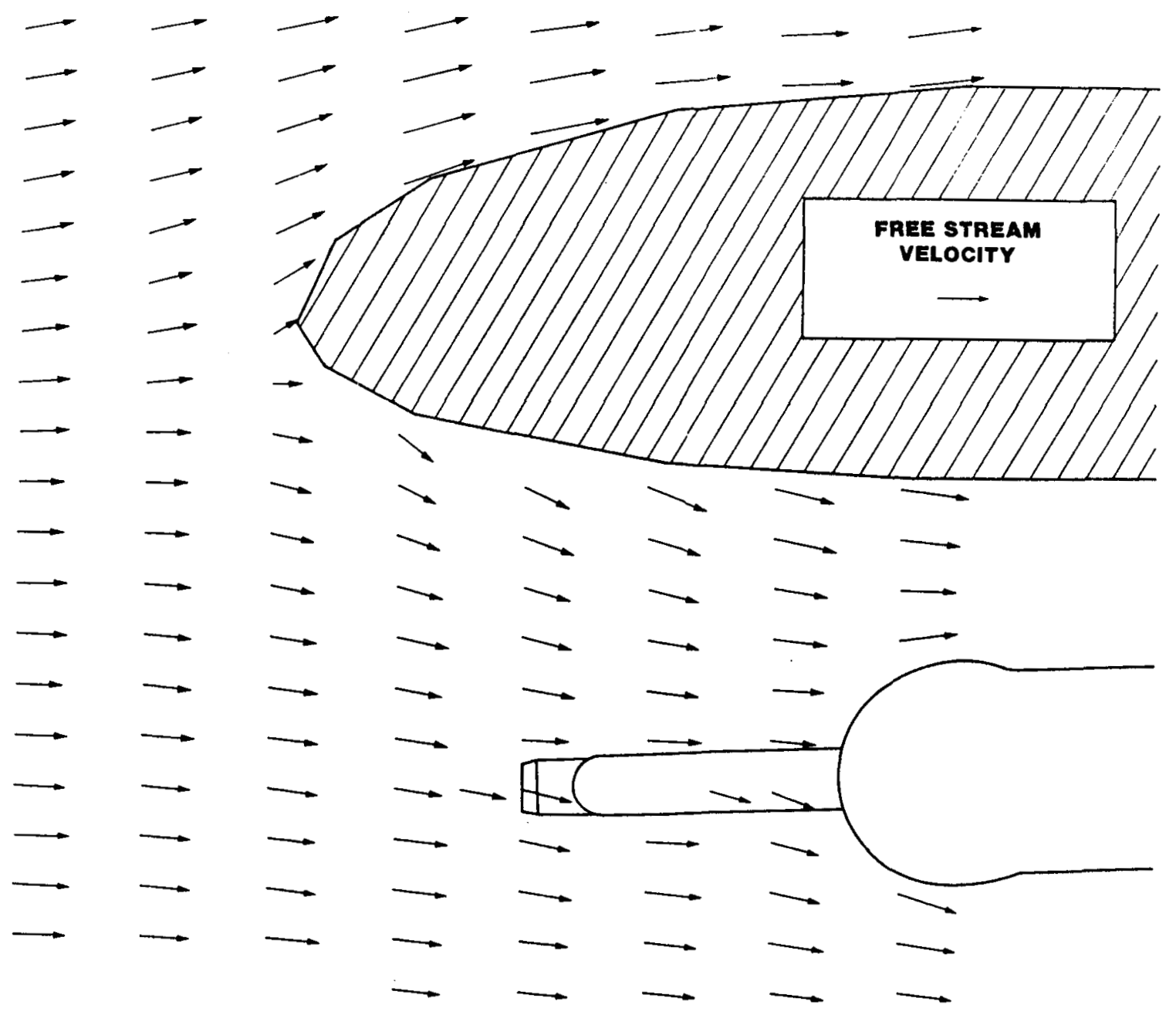

Figure 15. Flow field in a vertical plane parallel with the airplane fuselage axis and through the center point of the FSSP measurement tube intake orifice. The airplane fuselage axis is at $0^{\circ}$ angle of attack to the free stream flow. 


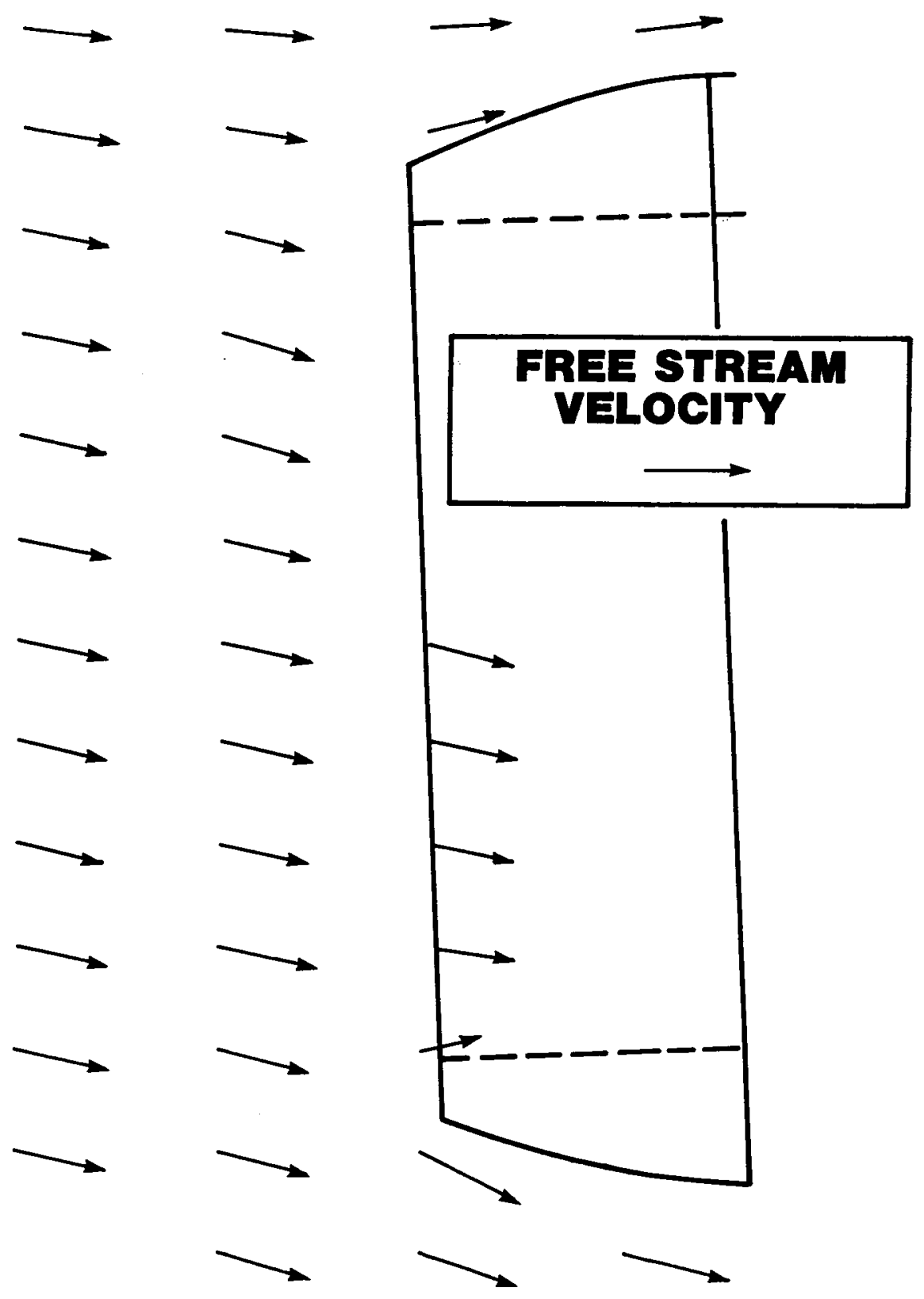

Figure 16. Flow into the FSSP measurement tube intake orifice. Plane of the figure and angle of attack are the same as for Fig. 15. 
Drop speed ratio is the ratio of water drop speed to the free stream air speed* at either: the center point of the laser beam for the OAP, or into the center of the measurement tube orifice for the FSSP. This quantity is important for the OAP because it is needed to produce undistorted two-dimensional images of hydrometeors. While common practice is to assume that drop transit speed through the laser beam is the same as airplane air speed, we see below that actually transit speed varies with: instrument, drop diameter, angle of attack and air speed.

In interpreting trajectory data it is important to understand the following generalities:

1. Large drops, which have high inertia, tend to ignore local flow perturbations such that the large-drop tails of plots of concentration factor or speed ratio vs. drop diameter approach unity.

2. Very small drops, which have small inertia, tend to closely follow the air flow such that the small-drop tails of plots of concentration factor vs. drop diameter show effects of flow divergence $\left(C_{F}<1\right)$ or flow convergence (i.e., streamline compression $)\left(C_{F}>1\right)$. Speed ratio asymptotically approaches that of the flow.

3. Intermediate sized drops tend to show less predictable effects. For example, plots of concentration factor or speed ratio vs. drop diameter may show maxima or minima, sometimes sharply peaked, depending on geometry, angle of attack and sometimes air speed.

Figures 17 through 21 show computer plots of portions of water drop flux tubes to the instruments. For the wing-mounted instruments all of the plots are for: $0^{\circ}$ airplane angle of attack, 95 kts free stream air

*For the wing-mounted instruments free stream speed corresponds to the airplane speed. 


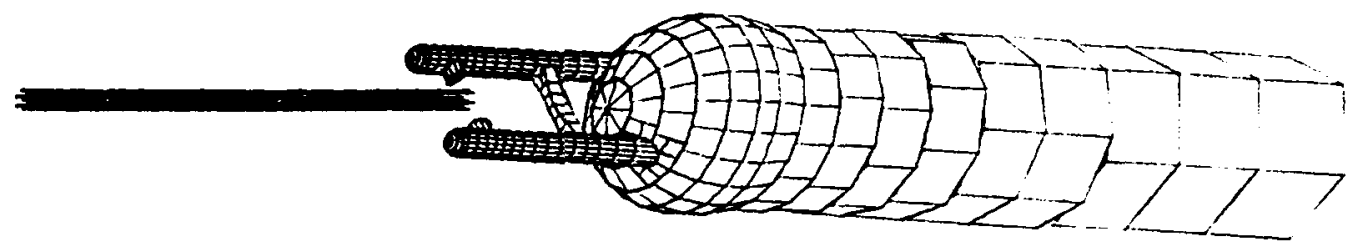

Figure 17. Flux tube of $20 \mu \mathrm{m}$ diameter water drops to the isolated OAP with the instrument axis at $4^{\circ}$ angle of attack to the free stream flow. $V_{\infty}=130 \mathrm{kts}$. 

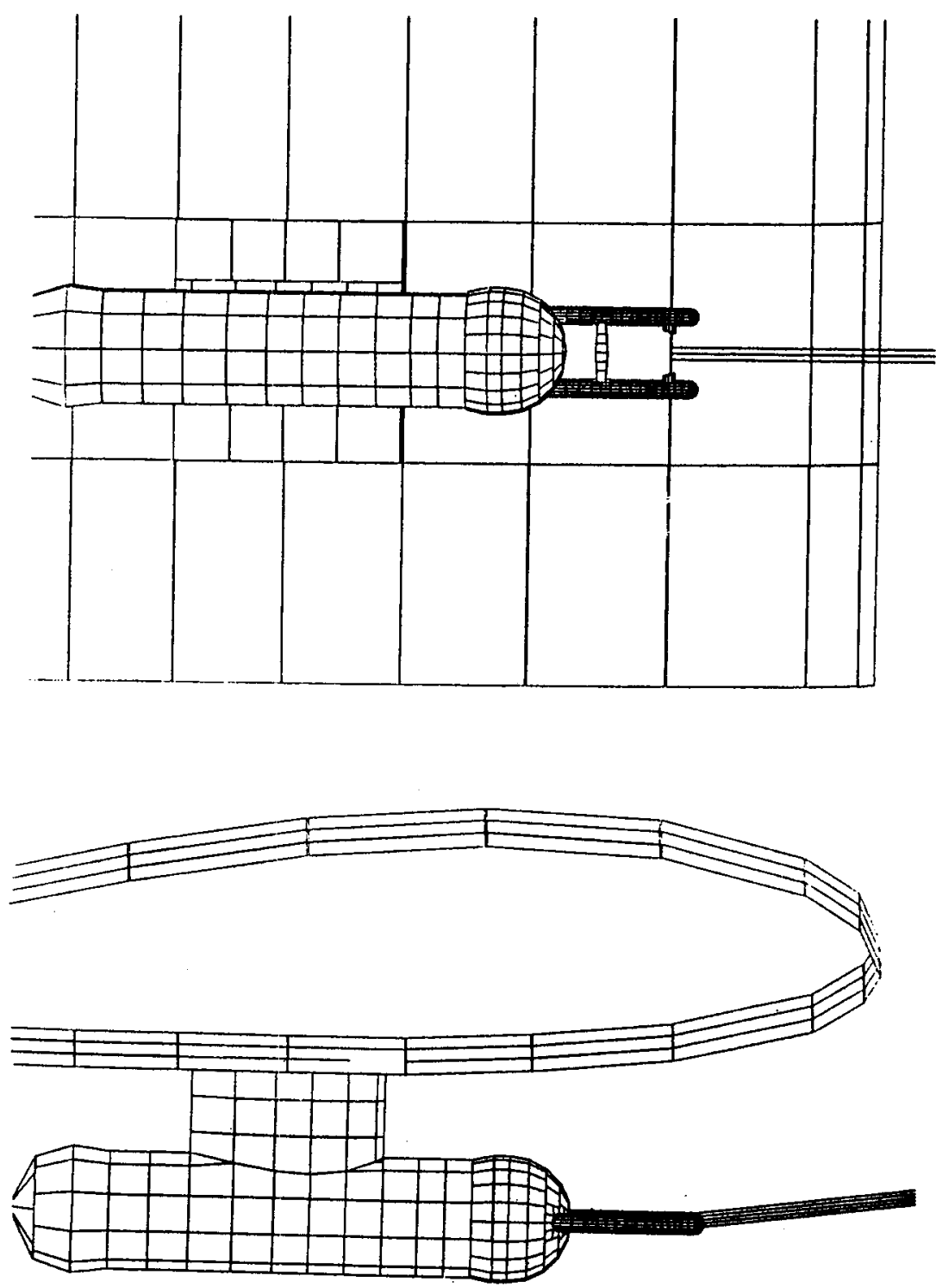

Figure 18. Flux tube of $1000 \mu \mathrm{m}$ diameter water drops to the wingmounted OAP. Airplane angle of attack is $0^{\circ}$. $V_{\infty}=95 \mathrm{kts}$. 

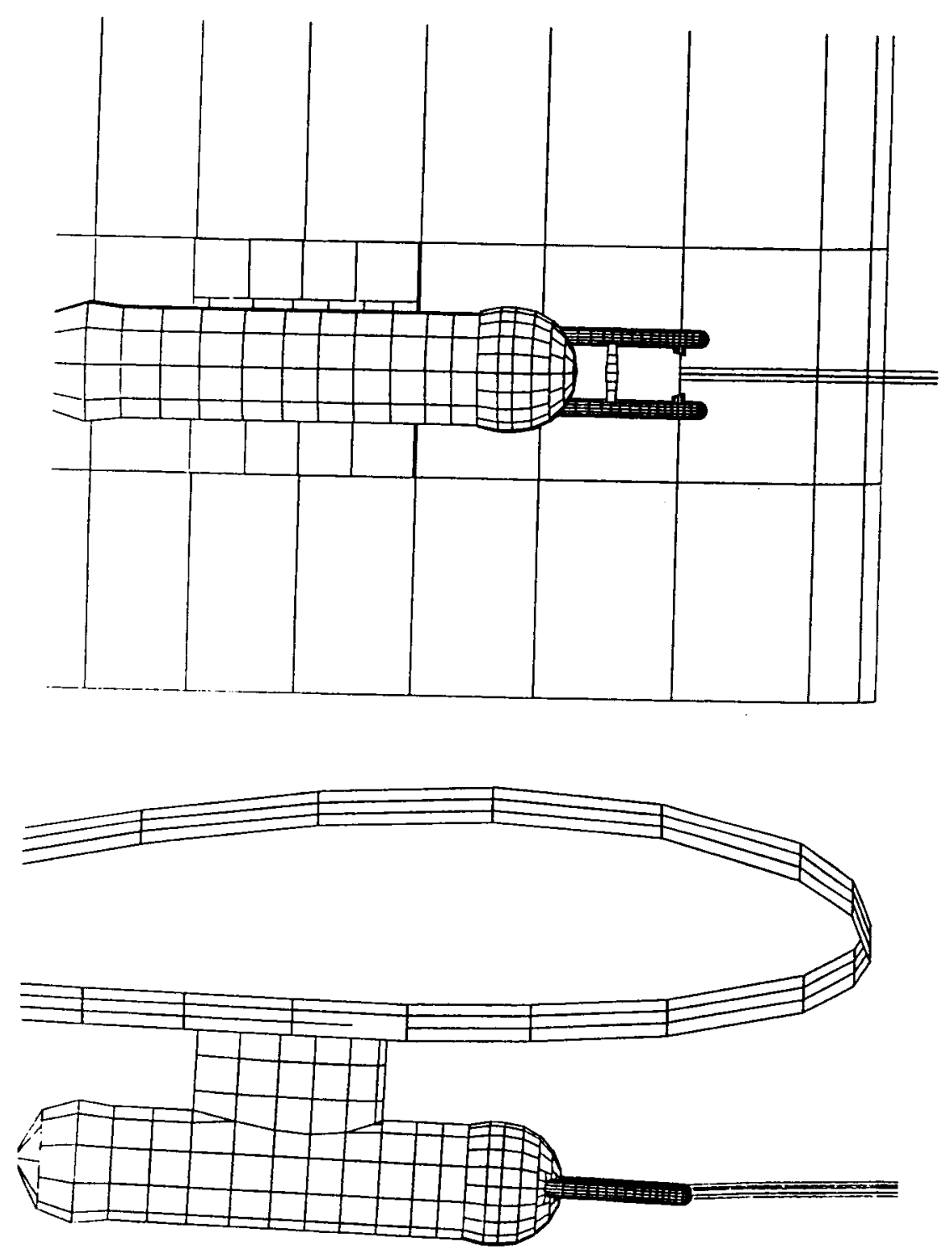

Figure 19. Flux tube of $100 \mathrm{~mm}$ diameter water drops to the wingmounted OAP. Airplane angle of attack is $0^{\circ}$. $V_{\infty}=95 \mathrm{kts}$. 

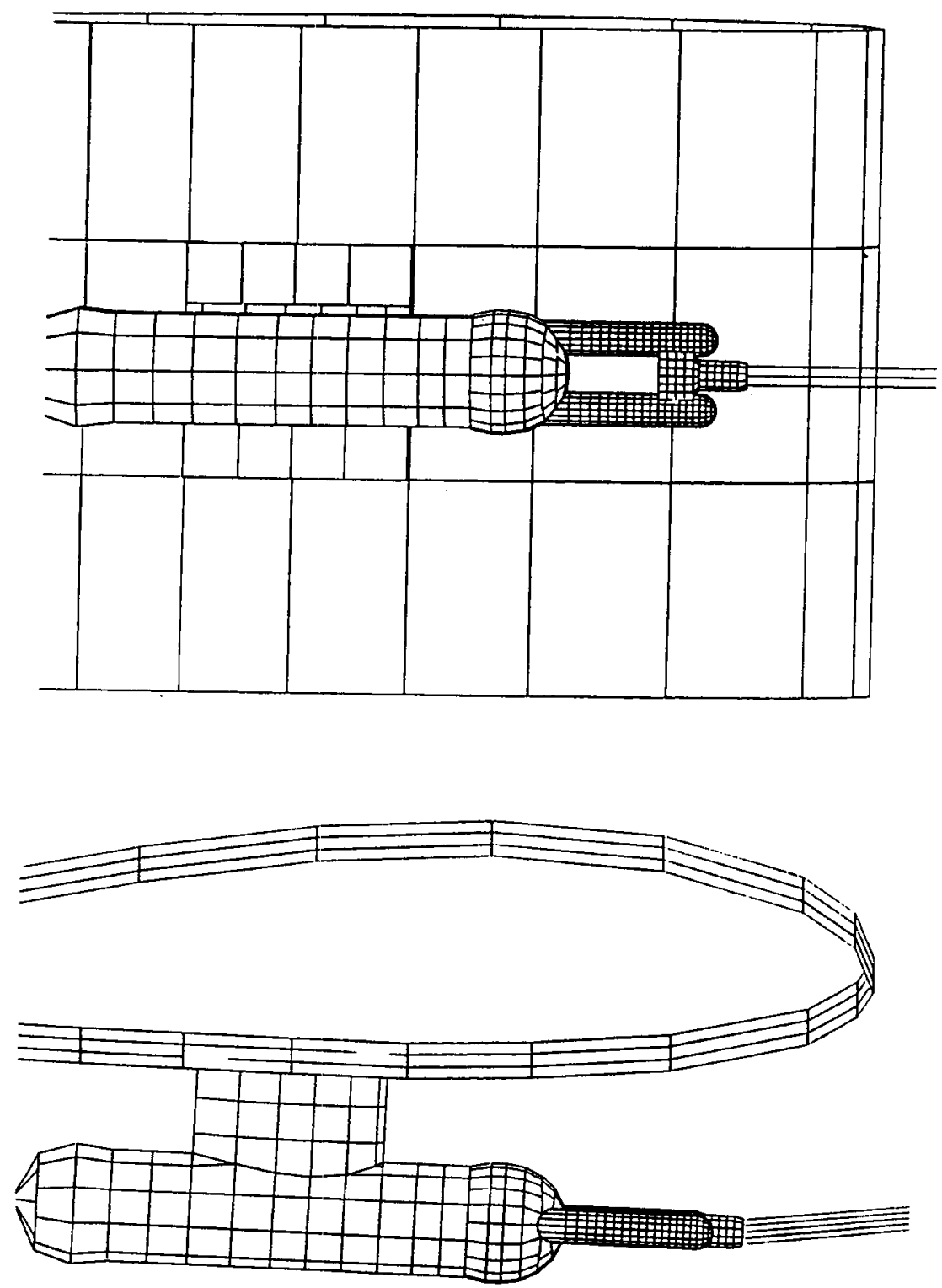

Figure 20. Flux tube of $1000 \mu \mathrm{m}$ diameter water drops to the wing-mounted FSSP. Airplane angle of attack is $0^{\circ}$. $V_{\infty}=95 \mathrm{kts}$. 

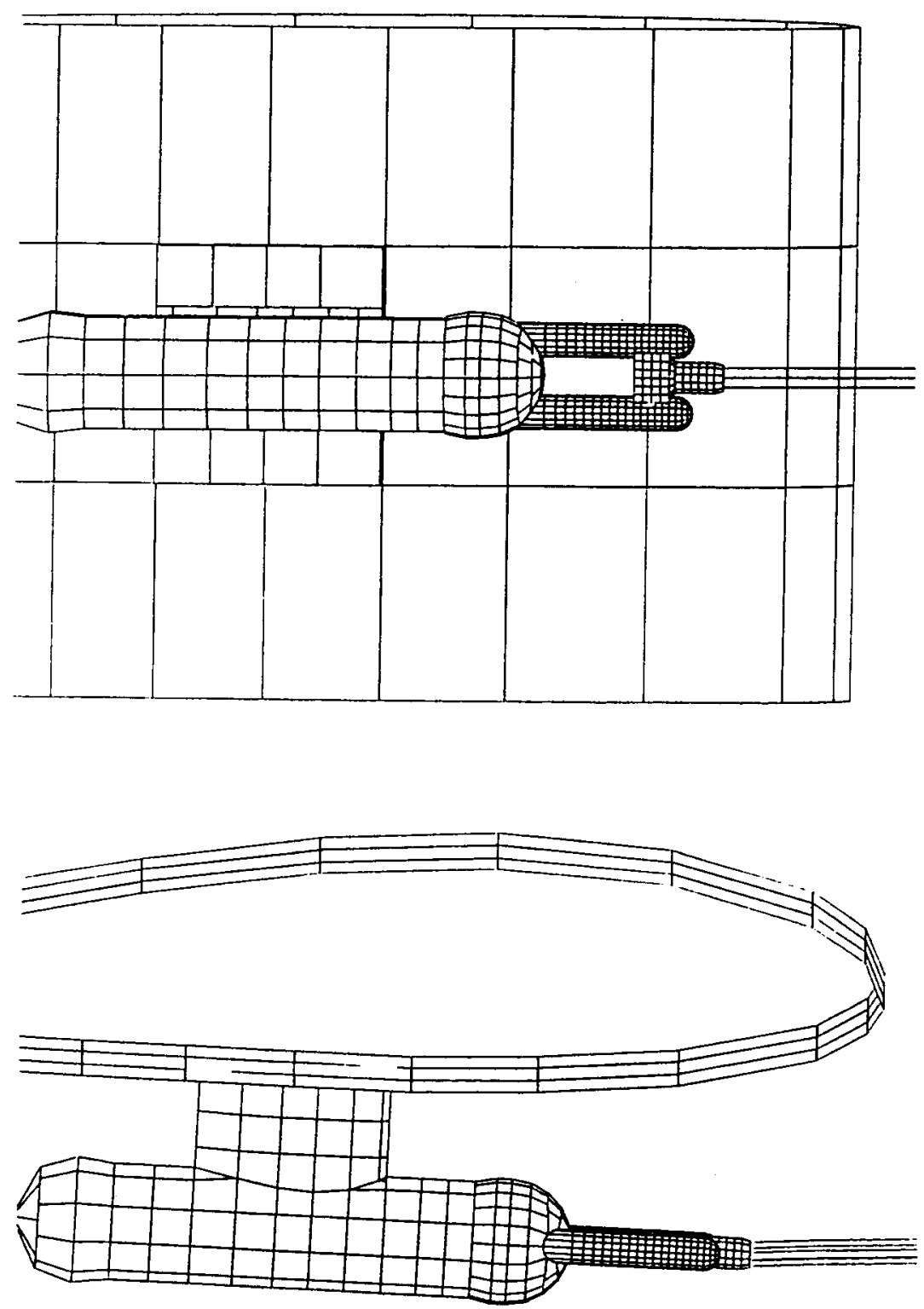

Figure 21. Flux tube of $100 \mu \mathrm{m}$ diameter water drops to the wing-mounted FSSP. Airplane angle of attack is $0^{\circ}$. $V_{\infty}=95 \mathrm{kts}$. 
speed and for water drops of 100 and $1000 \mu \mathrm{m}$ diameters. One important consideration made clear by the plots is that trajectories to or near the instruments are in no danger of intersecting the wing surface.

$\underline{\text { OAP }}$

Concentration factor results for the OAP are plotted versus water drop diameter in Figure 22, and Figure 23 shows a similar plot for speed ratio. Results for the isolated instrument and for the instrument mounted under the Twin Otter wing are included.*

For the isolated instrument, calculations were done for free stream air speeds of 95 and 250 knots, and for $0^{\circ}$ and $4^{\circ}$ angles of attack for each speed. There is little variation of concentration factor and speed ratio with either air speed or angle of attack so that average values are plotted. The slight fall-off of concentration factor and speed ratio as drop size decreases is caused by the effect at the laser beam of flow stagnation against the forward hemisphere of the canister (Fig. 5).

To fully understand results for the wing mounted instrument, it is necessary to more carefully consider flow conditions under the Twin Otter wing. Since at $0^{\circ}$ angle of attack the wing is tilted (leading edge up) $2.5^{\circ}$ relative to the free stream, there is a slight stagnation condition, with attendant slight divergence and reduction in flow speed, under the wing in the region immediately forward of the instrument (Fig. 14). This condition primarily affects drops in the intermediate size range (diameters in the approximate range 20 to $200 \mu \mathrm{m})$. However, further aft this stagnation condition is overcome by slight convergent flow that is required to negotiate the convex surface of the underside of the wing leading edge, and indeed, at the location of the laser beam, air flow speed is found to be slightly greater than free stream with the airplane at $0^{\circ}$ angle of attack and without the instrument (Appendix A). With the airplane at $4^{\circ}$ angle of attack, the under-wing partial stagnation condition

*A1l concentration factor and speed ratio results are tabulated in Appendix A. 


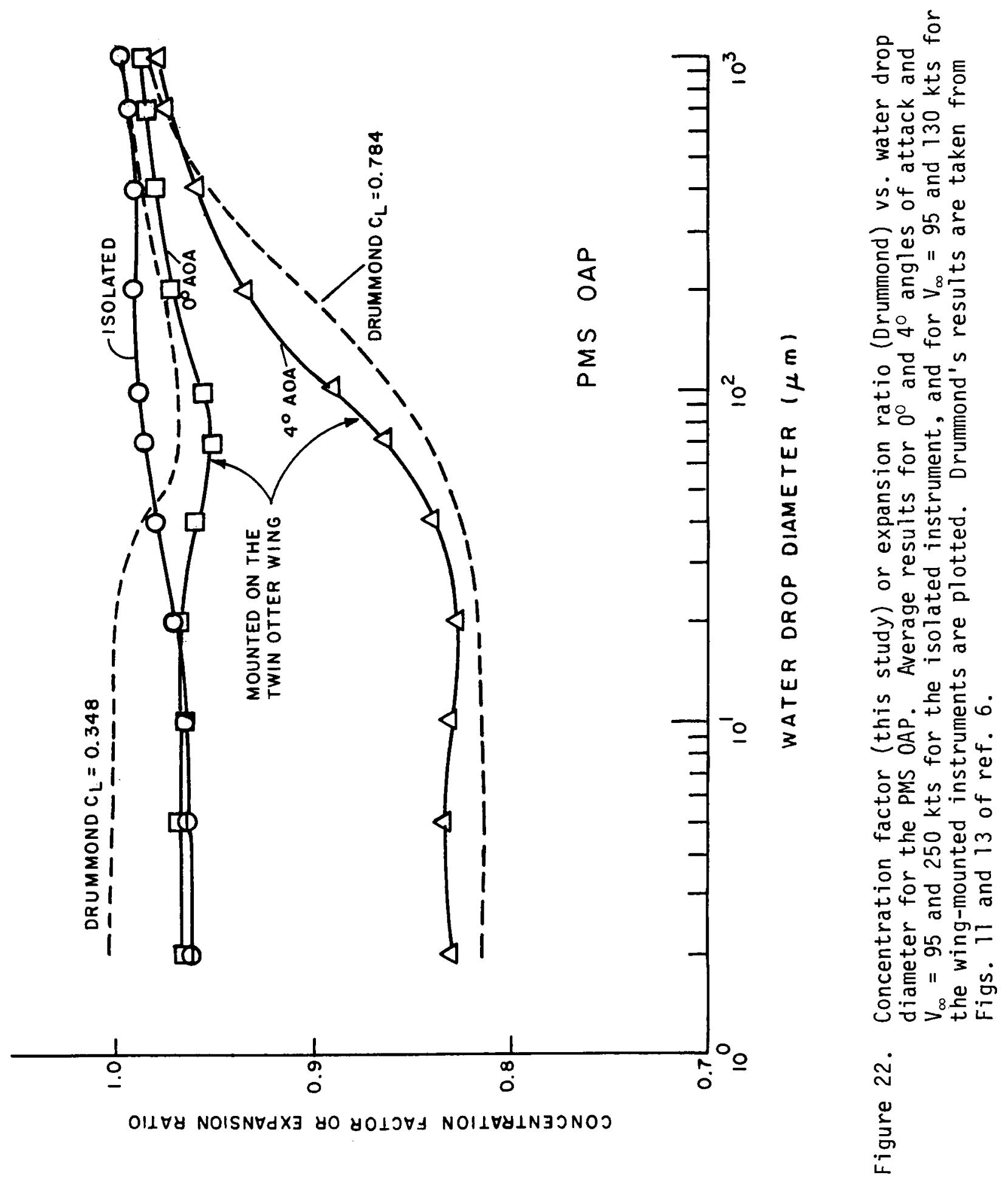




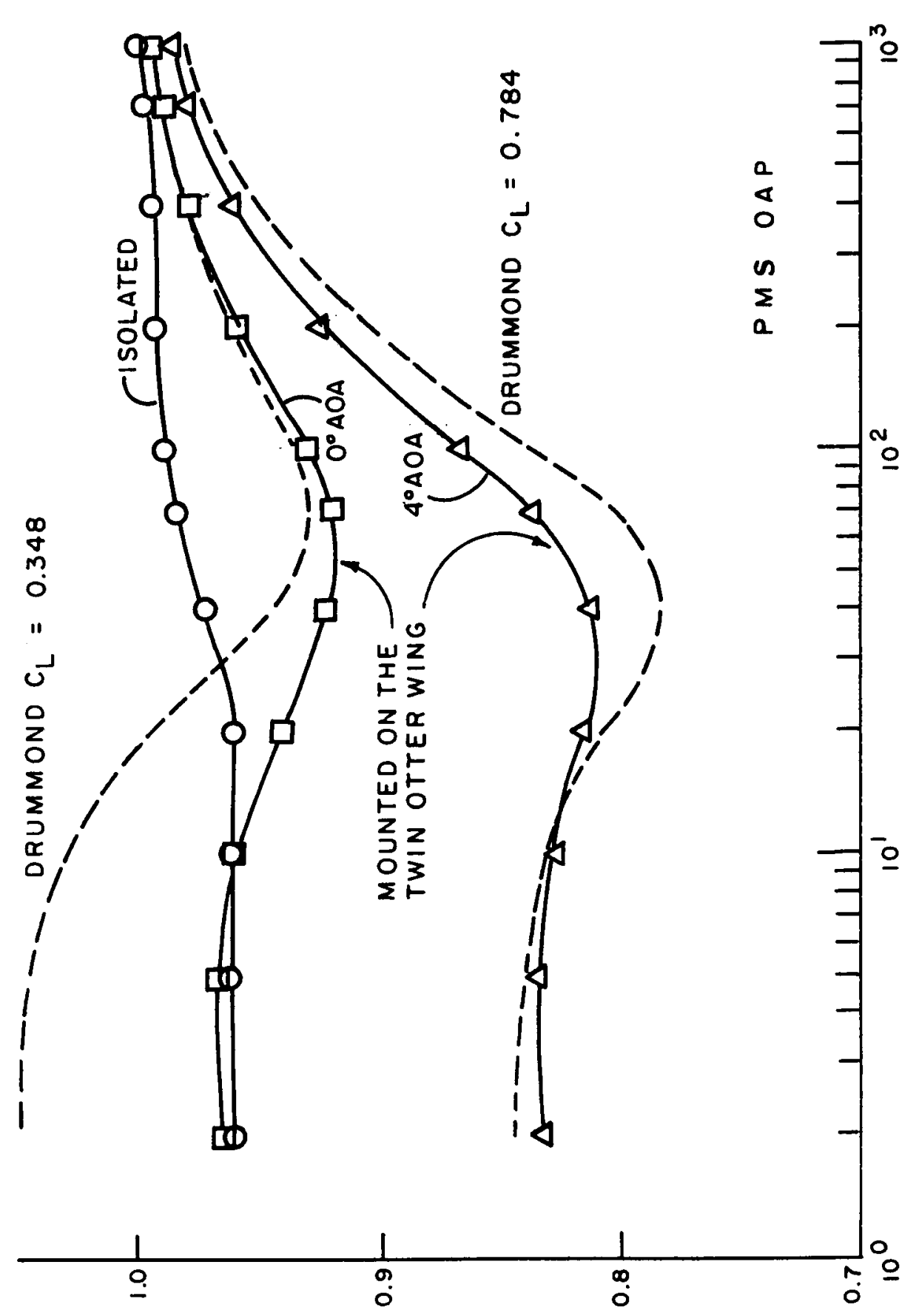

a

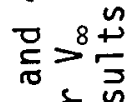

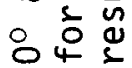
s믄 乐 ڤ

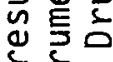
落. O

\& $0+$

$\geq+9$

- 10

w $\quad \therefore$ 은

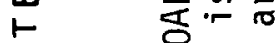

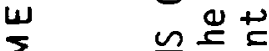

$\sum \quad \sum \frac{1}{2}$

万

0 ए थ

O

$\frac{\alpha}{0}$

4 웅

5 L 4

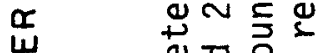

退 论 은 4

。

응 "

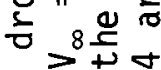

过 完

는

的范

+

임

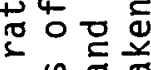

थ

뜽ำ

ज完 |

$\ddot{\sim}$

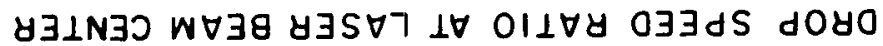

孚 
is, of course, more pronounced and prevails both forward of the instrument and at the location of the laser beam.

Flux and speed ratio results for the wing mounted OAP are completely consistent with this picture of the flow. For the airplane at $0^{\circ}$ angle of attack the curves in Figs. 22 and 23 show minima at about $70 \mathrm{rm}$ which are caused by the upstream stagnation effect on the midrange size drops. As drop size decreases, results rise slightly and level off slightly below unity principally because of the stagnation effect at the laser beam caused by divergent flow about the canister. For $4^{\circ}$ angle of attack, the falloff of the curves with decreasing drop size is much more dramatic, as well as more persistent, as expected. These results predict undermeasurement by about $17 \%$ for both flux and drop speed throughout the cloud droplet size range, when the airplane is at $4^{\circ}$ angle of attack.

It is particularly interesting to compare Figs. 22 and 23 with Figs. 24 and 25. (In Figs. 24 and 25 are plotted concentration factor and speed ratio vs. drop diameter at the location under the wing of the OAP laser beam, but with the instrument and its mount omitted.) This comparison indicates major contributions of the instrument itself to the distortions. At $0^{\circ}$ angle of attack roughly half of the divergence effects for intermediate size drops, and all for small drops is caused by the instrument. At $4^{\circ}$ angle of attack, slightly less than half of the effects for both intermediate and small drops are caused by the instrument. Implications of this are discussed below.

Also plotted in Figures 22 and 23 are results of a similar study by Drummond (refs. 5, 6). The Canadian National Aeronautical Establishment has a Twin Otter with an OAP mounted under its wing at the same location as the NASA OAP (Fig. 9b), and the Drummond studies were done for this instrument. The only difference in the Canadian instrumentation is that the mounting pylon (Fig. 10) is 1 " long compared with 5 " for the NASA pylon. This puts the laser beam at a distance of approximately 6" from the wing surface compared with 10" for the NASA instrument. Drummond used two-dimensional Joukowski airfoil theory to calculate 


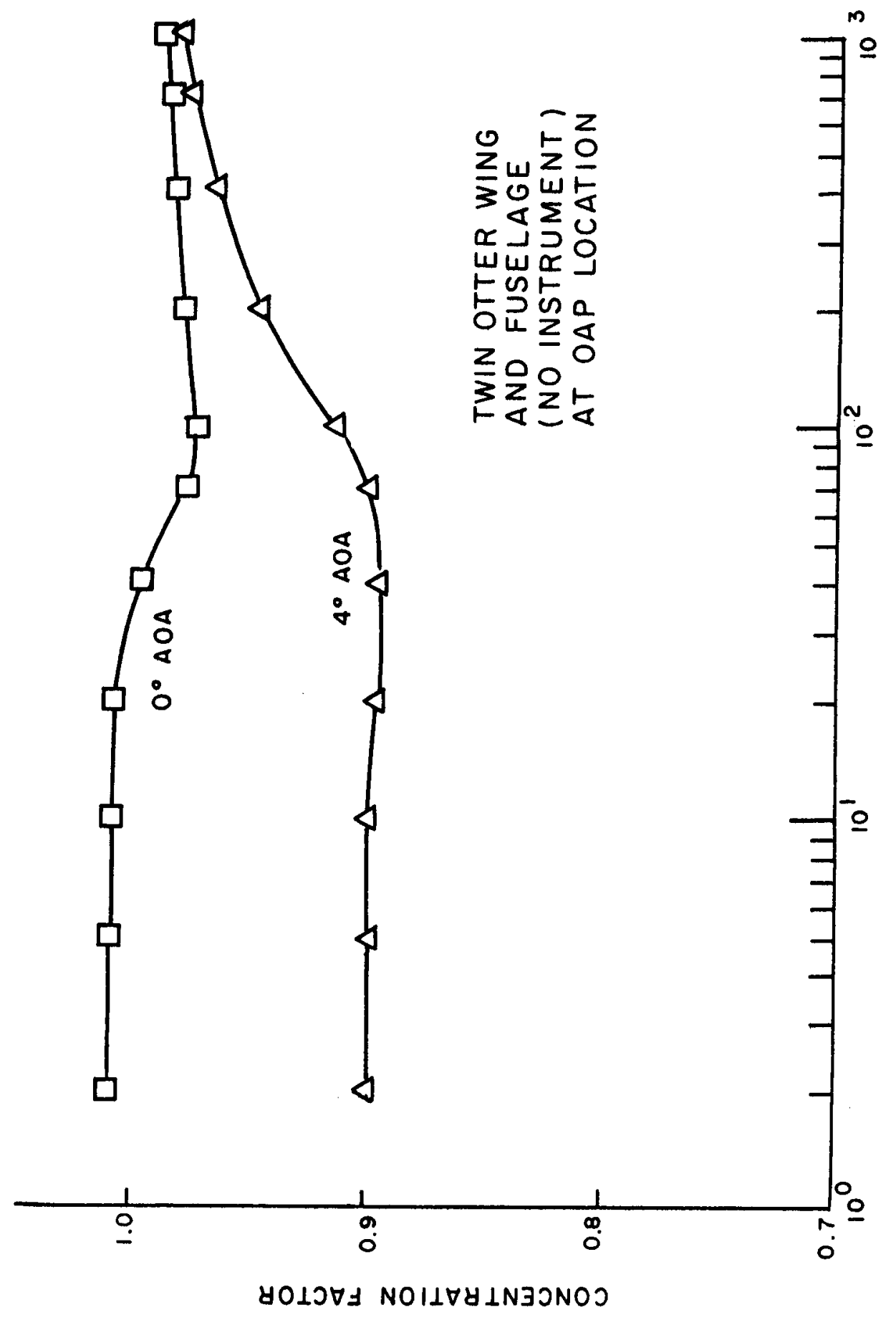

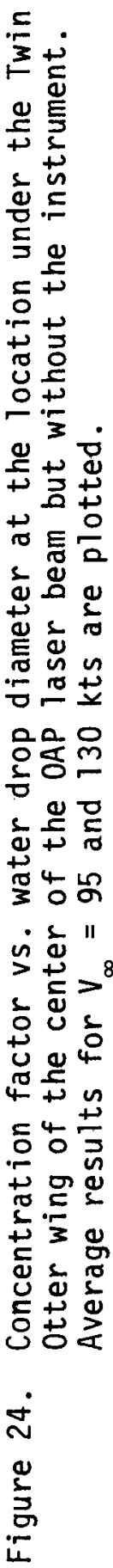




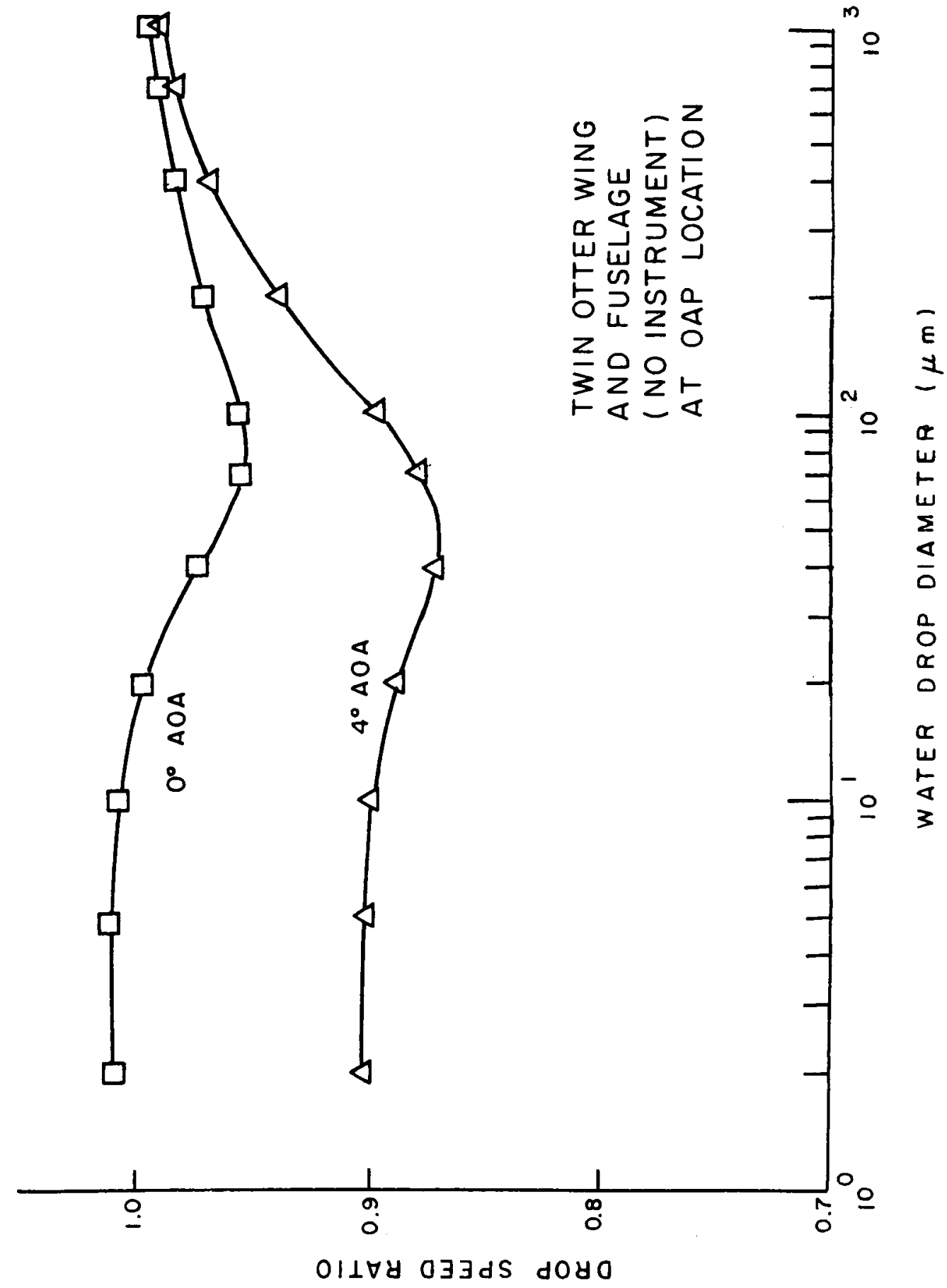

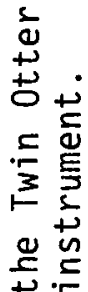

ฮิ ํㅗㄴ

至

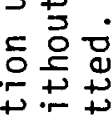

㟧 3

$0+0$

ه

岳

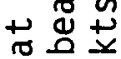

$2 \leqslant 0$

凹

車

이

ธू。

잉

$4>^{8}$

苟文

氠告

$>0$

오옹

$+5$

54.

용

离部文

ก่

告 
flow about the wing. Effects of the instrument on the flow were approximated by adding the potential function contribution for a sphere to that of the airfoil, the sphere being placed at the location of the forward canister hemisphere (Figs. 5, 10 and 14), while the remainder of the instrument structure was ignored. Expansion ratio (Fig. 22) is the twodimensional analog of concentration factor. Drummond's water drop trajectory calculation methods are discussed in detail in reference 6 . Drummond expresses flight conditions in terms of lift coefficient, $C_{L}$. Using data and equations given by Drummond we convert $C_{L}$ to wing angle of attack to arrive at the following:

\begin{tabular}{ccc}
$C_{L}$ & $\begin{array}{c}\text { Wing } \\
\text { Angle of } \\
\text { Attack }\end{array}$ & $\begin{array}{c}\text { Angle of Attack } \\
\text { In Terms of } \\
\text { Fuselage Axis }\end{array}$ \\
\hline 0.348 & $3.6^{\circ}$ & $1.1^{\circ}$ \\
0.784 & $8.0^{\circ}$ & $5.5^{\circ}$
\end{tabular}

As al ready noted, when mounted on the fuselage, the wing has a $2.5^{\circ}$ (leading edge up) angle of attack relative to the fuselage axis. In the rightmost column above we have subtracted $2.5^{\circ}$ from the wing angle of attack so that it can be compared with angle of attack as defined here. Thus, Drummond's $C_{L}=0.348$ corresponds roughiy with our $0^{\circ}$ angle of attack, and his $C_{L}=0.784$ corresponds roughly with our $4^{\circ}$ angle of attack. Comparisons of the corresponding curves in Figures 22 and 23 show good agreement between the results, in spite of the differences in geometry and calculation methods, except for the smallest droplets at the smaller angle of attack. For these cases Drummond's curves rise substantially higher than ours. This is probably caused by the fact that the Canadian instrument is 4 " closer to the wing surface where the flow is likely to be substantially more convergent. 
Results for the FSSP are plotted in Figs. 26-31. Concentration factors were calculated using flux tubes of two radij as described above on p. 23. Those calculated via the coarser flux tubes (solid curves in Figs. 26 and 27) predict overall collection efficiencies of the measurement tube, while those calculated via the finer flux tubes (broken curves in Figs. 26 and 27) predict collection efficiencies at the portion of the measurement volume inside of the measurement tube that is optically more active and that gives more accurate results.

For the isolated instrument, results (Figs. 26-29) are insensitive to change of angle of attack, as was also found for the OAP, but contrary to findings for the OAP, the results are slightly but significantly sensitive to change in air speed. For the instrument mounted under the Twin Otter wing, we find substantial sensitivity to angle of attack, as was also the case with the OAP, and in addition there is a consistent, though slight, sensitivity to air speed. Moreover, except for the largest drops, for which we expect little flux or speed distortion in any case, the distortions are more severe than for the OAP in all cases. Since differences in results at the two instrument locations without the instruments (compare Figs. 30 and 31 with Figs. 24 and 25) are minor*, it must follow that the bulk of the differences are caused by differences in flow around and through the instruments. This conclusion is particularly evident when results for the isolated instruments are compared. Thus, we find that the presence of the instruments, and even details of their geometries and operations, cause significant flow effects. This is an important finding since it has been common practice to assume that effects of flow perturbations caused by instruments themselves are not significant compared with effects caused by flow about the aircraft on which they are mounted.

\footnotetext{
*The most pronounced differences are for the $0^{\circ}$ angle of attack curves, which reflect differences in flow convergence under the wing at the measuring volumes of the two instruments. The OAP measuring volume is slightly closer to the wing surface, where there is slightly greater convergent flow, than is the case for the FSSP.
} 


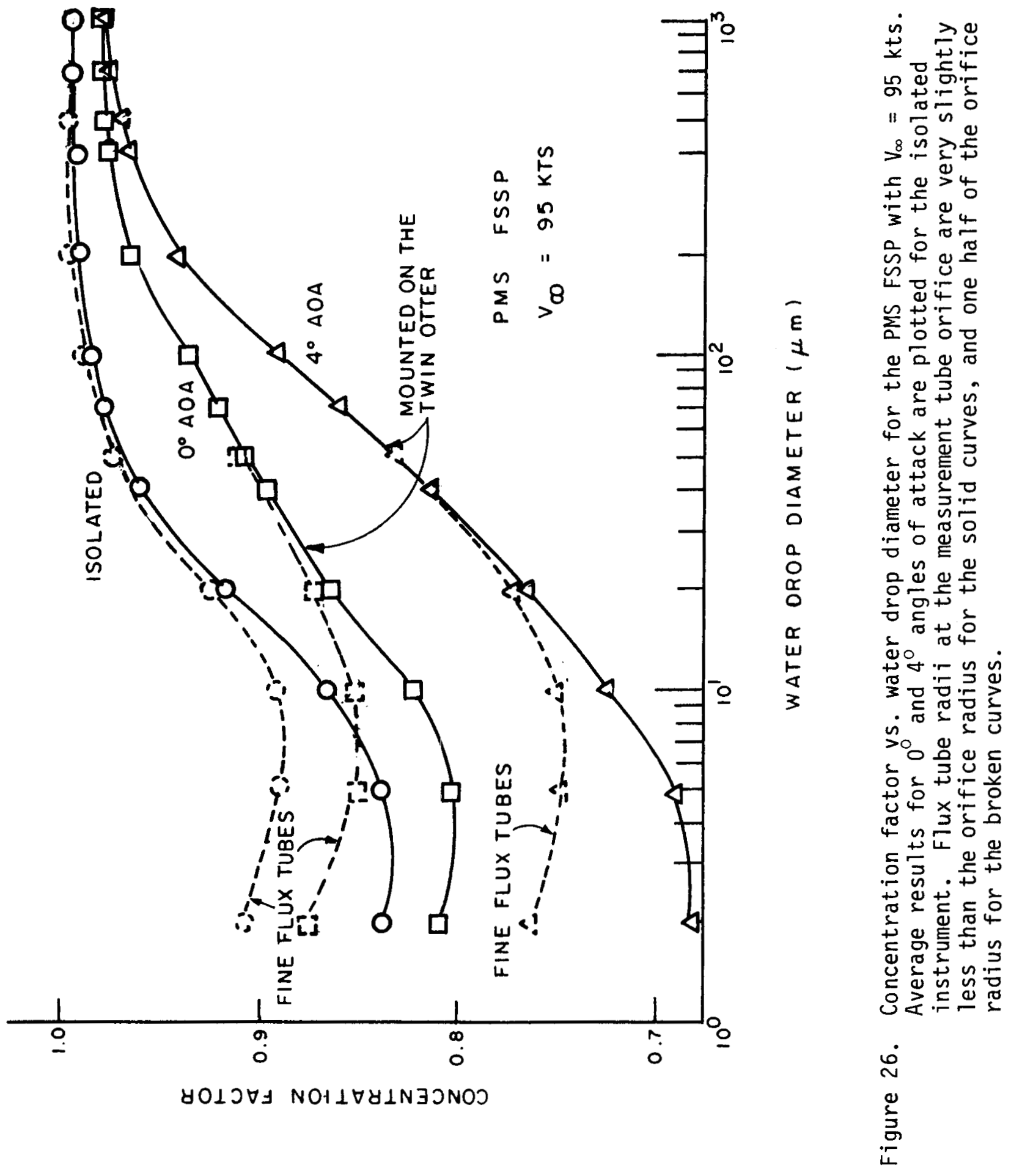




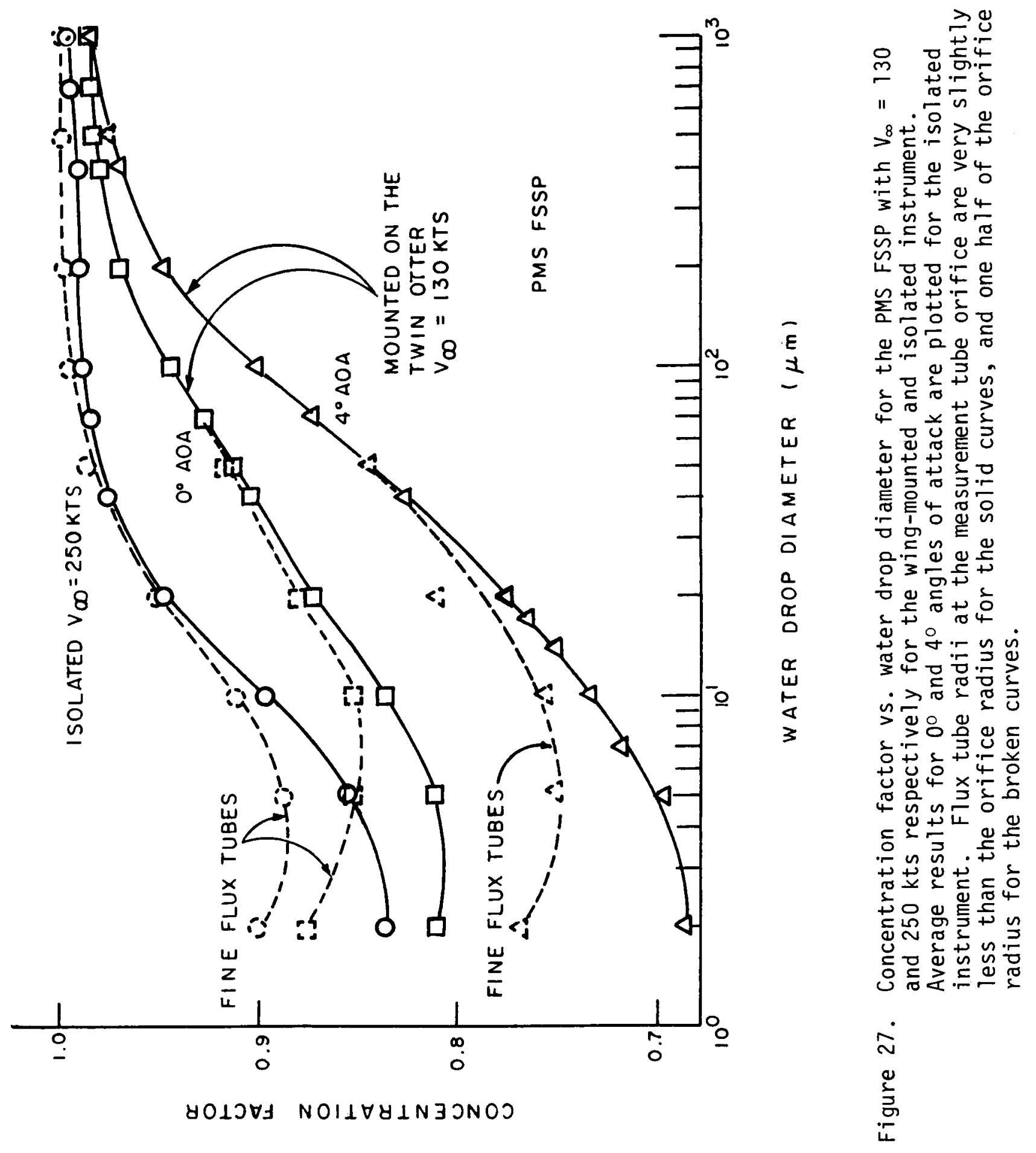




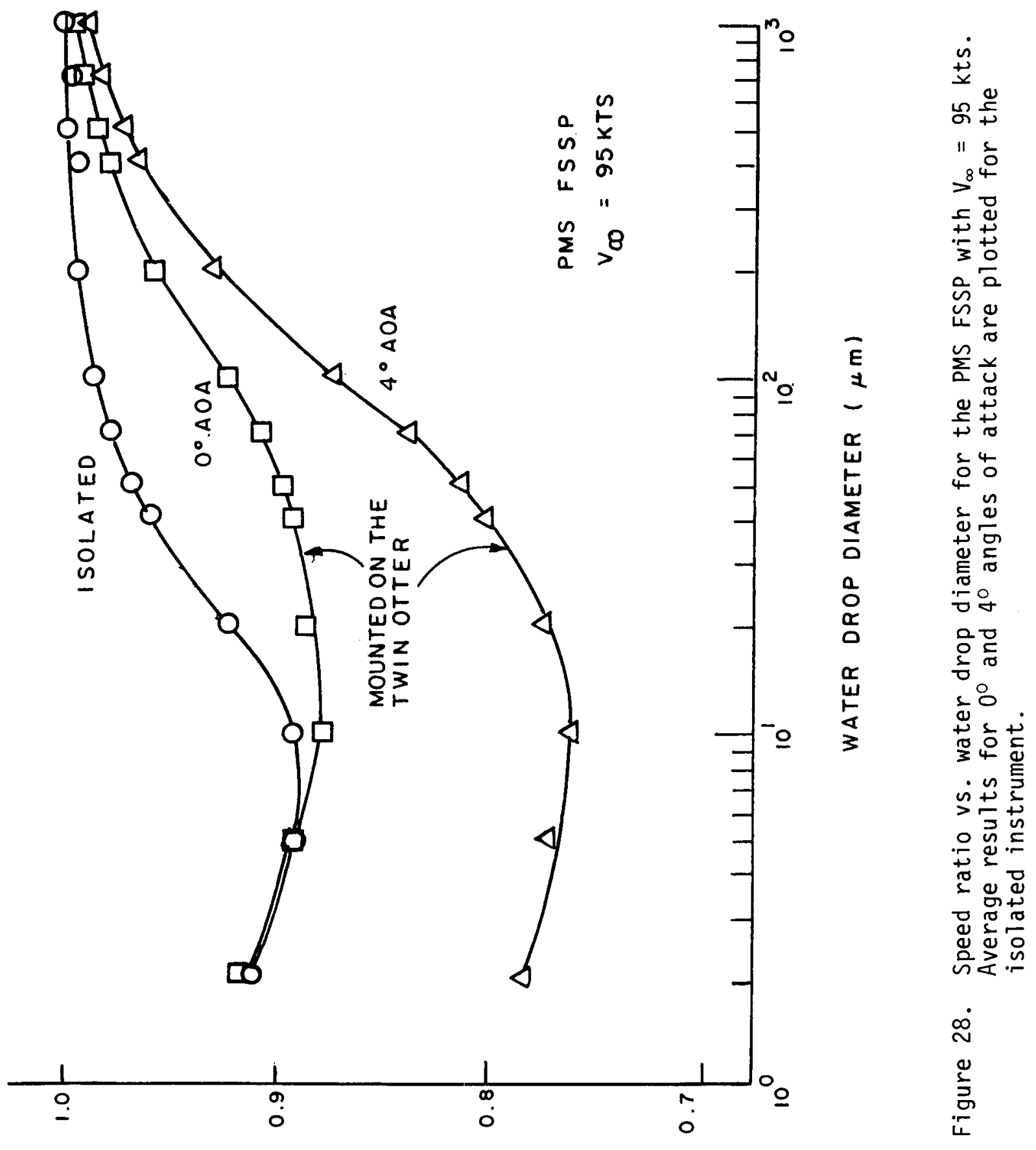

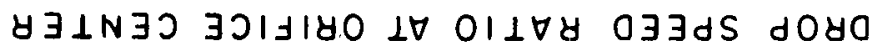




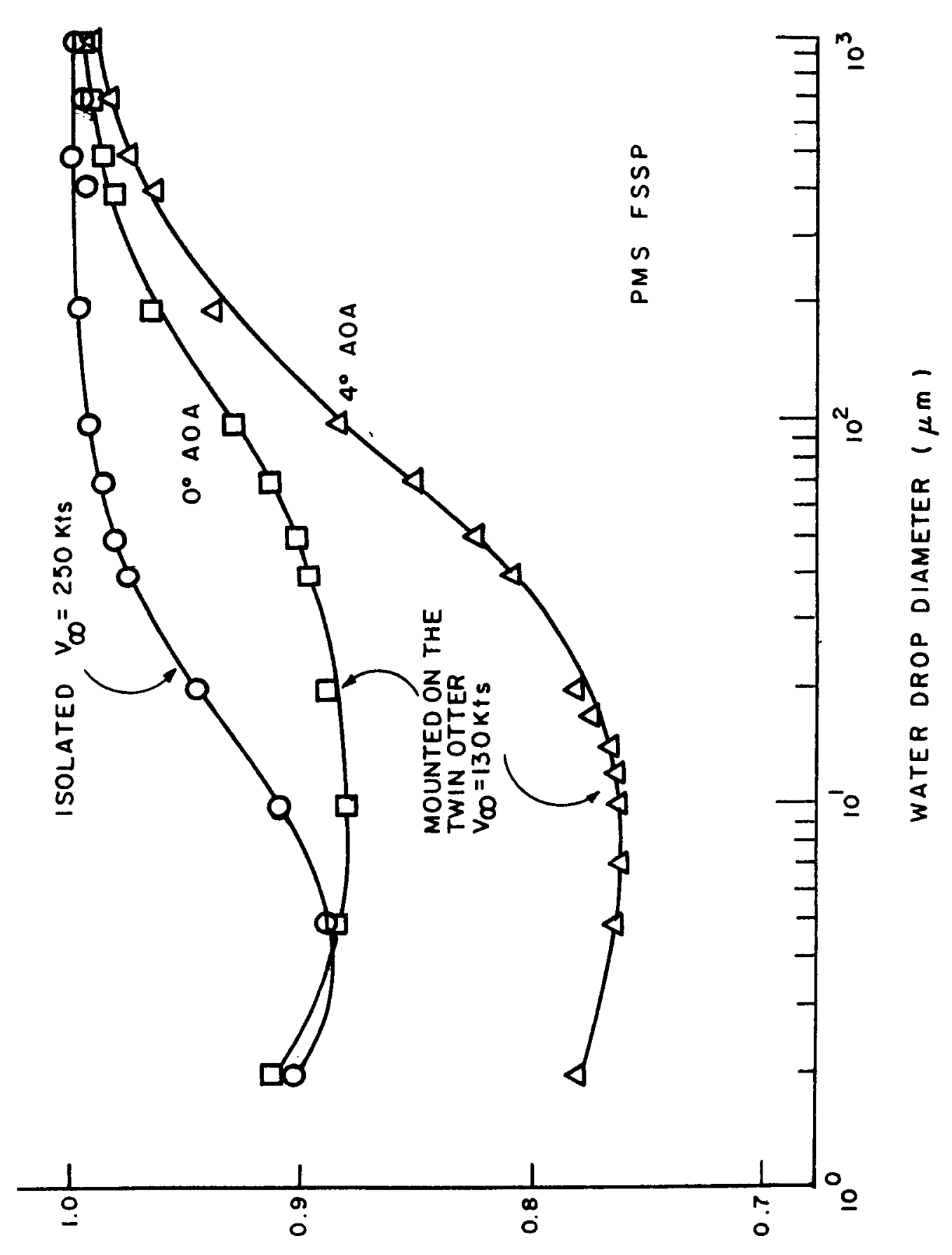

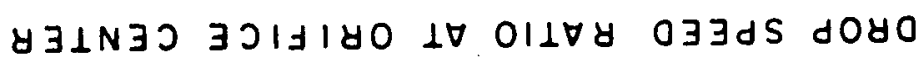




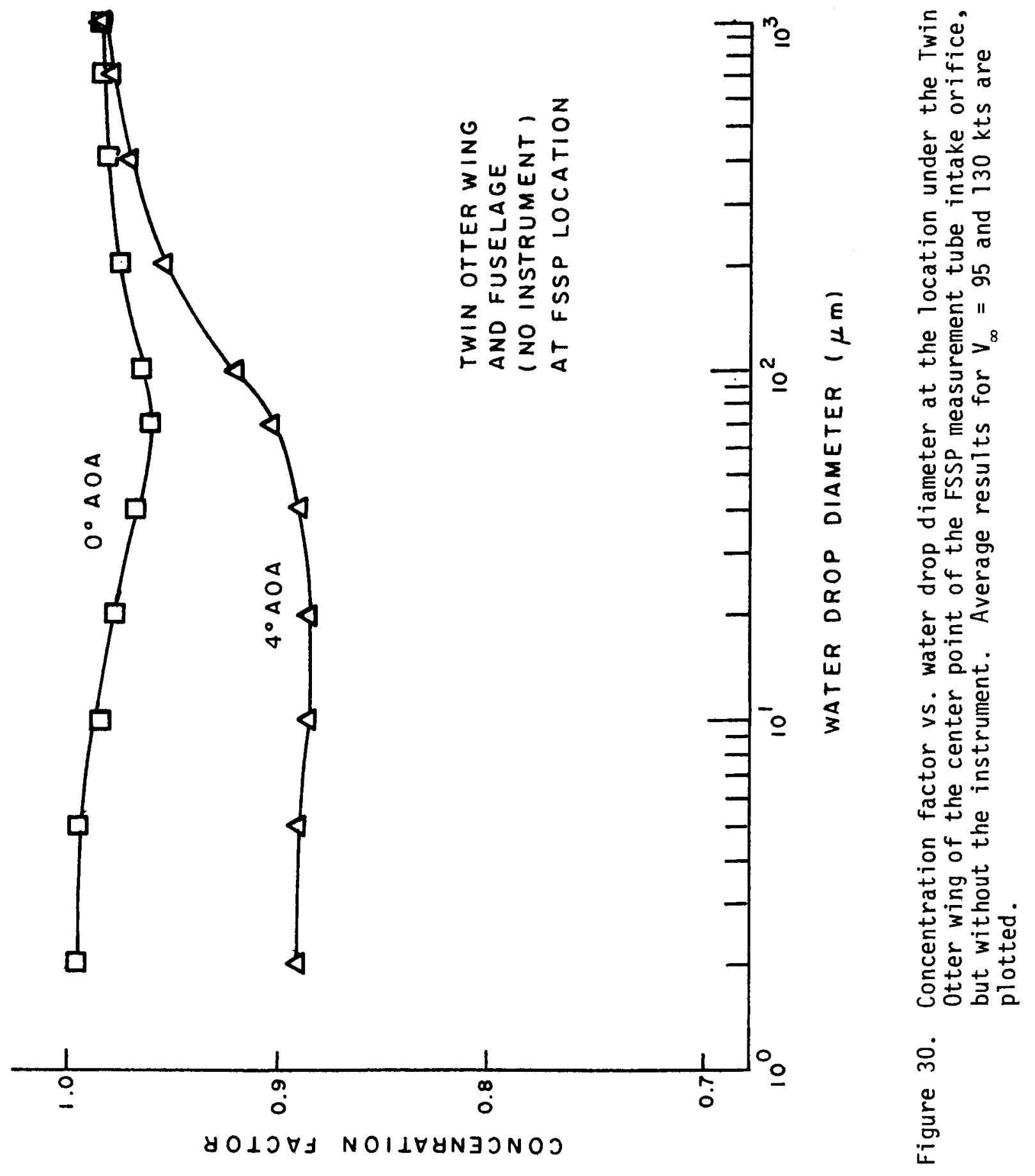



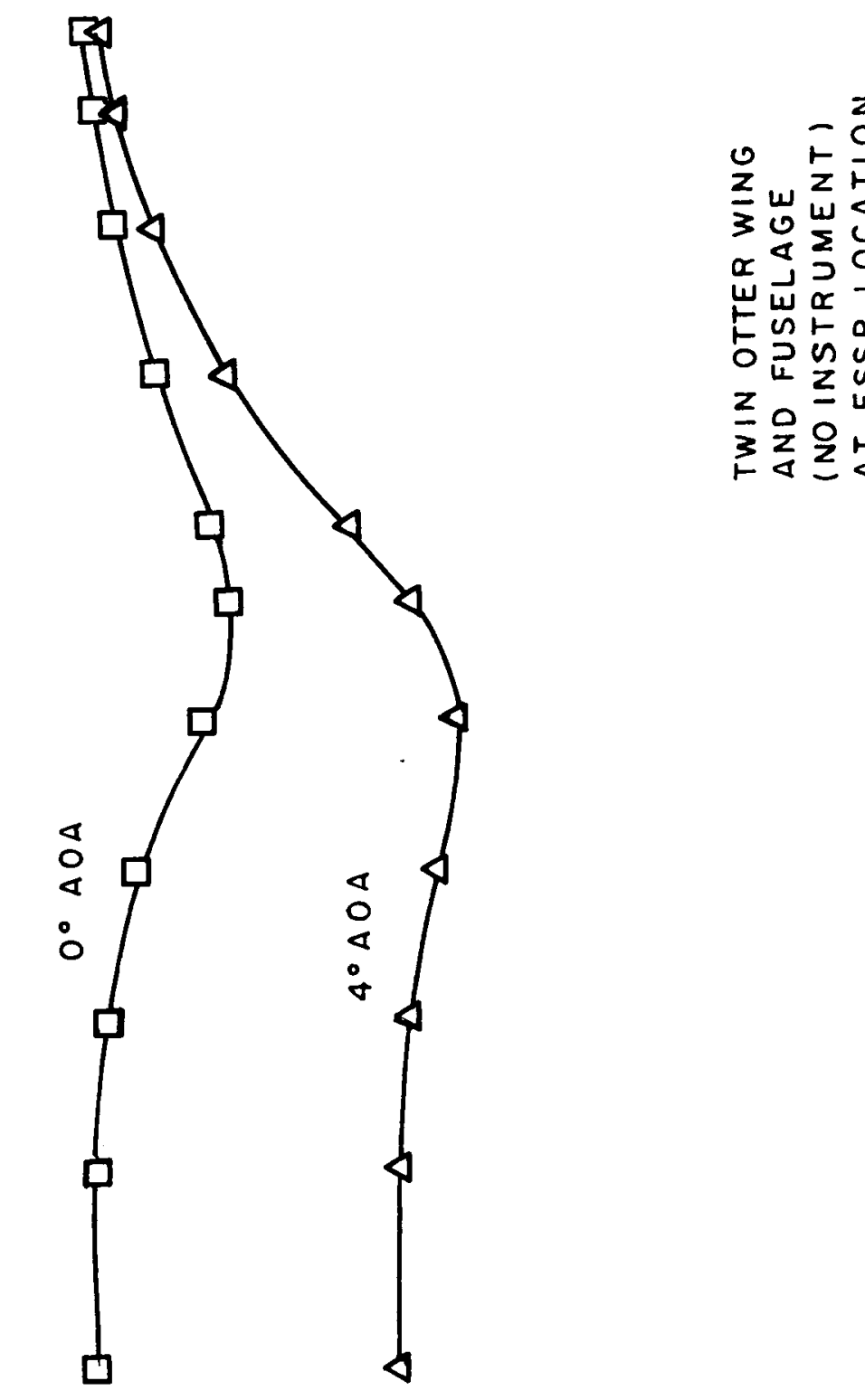

苛菩

苍 gั

$=.0 \%$

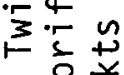

용ㅇ

觉

空

(

동요

-

E

$1 \quad 0$ 깅

은

约

$\underset{w}{\square} \quad$

$+\widetilde{\sigma}$

पै

워

ฮ气 ป

嵌

告交

t).

के음

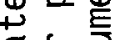

学稀

i $气$ U

웋

$\pi 4$

으을

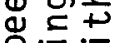

in 3

mं

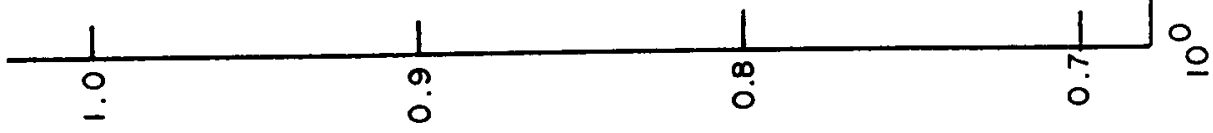

号

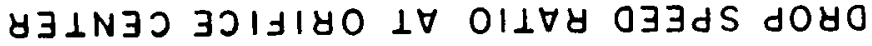


Regardless of whether we consider the solid or broken curves in Figs. 26 and 27 , we predict significant flux distortions for droplets in the cloud droplet size range (diameters $\approx 50 \mu \mathrm{m}$ ). Quantitatively, these results predict flux measurement errors by the Twin 0tter FSSP on the order of 12 to $25 \%$ - caused by flow perturbations alone. The reasons for this are clear. Not only does the structure of the support arm-measurement tube combination present a considerable obstacle to the flow, but the air and drops must enter and traverse the measurement tube.

As discussed above (pp. 17, 18) air flux through the measurement tube is reduced $8 \%$ relative to free stream for the isolated instrument, while for the wing mounted instrument, flux into the tube center is reduced by 10 and $23 \%$ relative to free stream for $0^{\circ}$ and $4^{\circ}$ angles of attack (see the table on p. 26). The results in Figs. 26 through 29 are consistent with this. As noted previously, both concentration factor and speed ratio approach air flux (i.e., air speed) values as particle size approaches zero, whereas for large, massive particles both concentration factor and speed ratio are essentially unity. Thus, concentration factors calculated from the finer flux tubes (broken curves in Figs. 26 and 27) and speed ratios (Figs. 28 and 29) are expected to approach the values of $92 \%$ (isolated instrument), 90\% (wing mounted, at $0^{\circ}$ angle of attack) and $77 \%$ (wing mounted, at $4^{\circ}$ angle of attack) for the smallest droplets. (Concentration factor curves calculated from the coarser flux tubes are expected to approach lower minima for small droplets because the coarser tubes are more affected by diverging flow about the tube orifice edges and other obstructing structures.) These expectations are essentially realized for speed ratios in all cases, and for the concentration factors at $4^{\circ}$ angle of attack for the wing mounted FSSP. On the other hand, concentration factor curves for the isolated and wing mounted FSSP at $0^{\circ}$ angle of attack pass through minima at about $7 \mu \mathrm{m}$ droplet diameter and then rise fairly sharply toward the small-drop limit. It is surprising 
for droplets as small as $2 \mu \mathrm{m}$ that concentration factors remain considerably below the limits, though the data indicate that the limits would be finally reached by still smaller droplets.

\section{Preferred Orientation}

Preferred orientation of hydrometeors can be studied by examination of their drag vectors. It is well known that for Reynolds numbers large enough to indicate nonviscous flow but not so large as to indicate unsteady motion, hydrometeors orient such as to present maximum resistance to movement. Thus water drop flattening planes, ice column long axes and ice plate faces all orient normal to their drag vectors. Moreover, Beard (ref. 18) has shown that, at least for water drops, response time is short enough to allow reorientation to occur along curved trajectories at normal flight speeds. It is particularly important to know orientation of hydrometeors as they pass through the measurement volume of a two-dimensional imaging OAP spectrometer so that the images can be properly interpreted. Water drop drag vectors at final points of flux tube central trajectories (i.e., at the centers of the instrument sampling volumes) as tabulated in Appendix B. These data predict that orientation varies significantly with all of: drop size, angle of attack and free stream air speed. Moreover, the complexity of the data, particularly for the wing-mounted instruments, indicates that additional study is warranted. 


\section{CONCLUSIONS}

\section{ISOLATED INSTRUMENTS}

For the OAP we predict insensitivity of both concentration factor (i.e., flux ratio) and speed ratio* to both angle of attack and free stream airspeed. The only distortions are slight slowing and slight flux divergence for small droplets caused by an upstream effect, at the location of the laser beam, of flow stagnation against the forward hemispherical end of the canister (Fig. 5). These distortions are of little practical importance.

The FSSP presents greater obstruction to flow than the OAP owing to the presence of the measurement tube and to the large size of its support arms (compare Figs. 5 and 6 ), and in addition requires that both air and drops traverse the interior of the measurement tube. Again no angle of attack effects are found, but persistent free stream air speed effects are found in the diameter range from about 5 to $50 \mu \mathrm{m}$ for both concentration factor and drop speed ratio, though these effects are of no practical significance. Both concentration factor and speed ratio approach limits of about 0.9 for small drops, which is consistent with our estimate of air flux through the measurement tube. The results predict that flux measurements of droplets in a size range typically found in clouds (diameters $\tilde{<} 20 \mu \mathrm{m}$ ) would be too low by about $10 \%$. Measurements of rain-size drops are little affected by the flow.

\section{WING-MOUNTED INSTRUMENTS}

For the OAP, results are found to be insensitive to free stream air speed, but substantial angle of attack effects are found. At $0^{\circ}$ angle of attack, distortions of drop flux and speed are small enough to be of little practical consequence. However, at $4^{\circ}$ angle of attack significant decreases in both drop speed and flux are found for droplets with diameters less than about $150 \mu \mathrm{m}$. Much of this is cause by partial flow

\footnotetext{
*Flux and speed ratios are for water drops at the instrument sampling volumes
} relative to free stream values. 
stagnation against the under side of the uptilted wing. Minima in curves of concentration factor and speed ratio vs. drop diameter are 0.83 and 0.81 respectively. The concentration factor curve remains constant at its minimum value for drop diameters less than $20 \mu \mathrm{m}$. The speed ratio curve reaches its minimum at about $30 \mu \mathrm{m}$, and then rises to stabilize at about 0.83 for smaller drops. These results predict undermeasurement by about $17 \%$ of both flux and transit speed through the laser beam for all cloud-size droplets, when the airplane is at $4^{\circ}$ angle of attack. Our results agree well with the two-dimensional calculation results of Drummond (refs 5,6).

For the FSSP we again find very significant angle of attack effects on both drop flux and speed ratios and in 211 cases, the distortions are substantially greater than are found for the OAP. Air speed effects are persistent for small drops, but are of no practical significance. For small droplets, in the cloud droplet size range, we predict undermeasurement of both flux and speed of about $10-13 \%$ at $0^{\circ}$ angle of attack, to about $24 \%$ at $4^{\circ}$ angle of attack. We repeat that these errors are caused by effects of flow perturbations alone. Measurements of rain-size drops are little affected by the flow

Comparisons of results calculated with and without the instruments mounted under the Twin Otter wing show that roughly half of the flux and speed distortions are caused by the presence of the instruments themselves. This finding is quite significant because it has been common practice to ignore the presence of instruments on the assumption that flow perturbation effects caused by them are not likely to be signficant compared with those caused by the aircraft on which they are mounted.

\section{PREFERRED ORIENTATION}

Drop drag vector angles at the instrument measurement volumes appear to be rather complex functions of drop size, angle of attack and free stream air speed (Appendix B). This needs additional study because of its implications with regard to preferred orientations presented to the instruments of: flattened water drops, ice columns and ice plates. 


\section{APPENDIX A}

CONCENTRATION FACTOR AND SPEED RATIO DATA

I solated OAP

\begin{tabular}{|c|c|c|c|c|c|c|c|c|}
\hline \multirow{3}{*}{$\begin{array}{c}\text { Water } \\
\text { Drop } \\
\text { Diameter } \\
(\mu \mathrm{m}) \\
\end{array}$} & \multicolumn{4}{|c|}{$-0^{\circ} \mathrm{AOA}$} & \multicolumn{4}{|c|}{$\longrightarrow 4^{\circ} \mathrm{AOA}=$} \\
\hline & $V_{\infty}=95$ & $5 \mathrm{kts}$ & \multicolumn{2}{|c|}{$v_{\infty}=250 \mathrm{kts}$} & \multicolumn{2}{|c|}{$v_{\infty}=95 \mathrm{kts}$} & \multicolumn{2}{|c|}{$V_{\infty}=250 \mathrm{kts}$} \\
\hline & $\mathrm{C}_{\mathrm{F}}$ & $v_{p}$ & $C_{F}$ & $v_{p}$ & $\mathrm{C}_{\mathrm{F}}$ & $v_{p}$ & $C_{F}$ & $v_{p}$ \\
\hline 1000 & .997 & 1.002 & .997 & .999 & .997 & 1.002 & .997 & .999 \\
\hline 700 & .994 & .998 & .994 & .997 & .994 & .998 & .994 & .997 \\
\hline 400 & .991 & .994 & .991 & .994 & .991 & .994 & .991 & .994 \\
\hline 200 & .990 & .993 & .991 & .994 & .990 & .993 & .991 & .994 \\
\hline 100 & .987 & .988 & .990 & .991 & .987 & .988 & .990 & .991 \\
\hline 70 & .984 & .984 & .988 & .989 & .984 & .984 & .988 & .989 \\
\hline 40 & .976 & .973 & .983 & .982 & .977 & .973 & .983 & .982 \\
\hline 20 & .965 & .960 & .972 & .968 & .966 & .961 & .972 & .968 \\
\hline 10 & .965 & .961 & .963 & .959 & .966 & .962 & .964 & .960 \\
\hline 5 & .963 & .961 & & & & & & \\
\hline 2 & .961 & .959 & & & & & & \\
\hline$v_{a}$ & .9 & 58 & & 58 & & 59 & & 59 \\
\hline
\end{tabular}

OAP Mounted Under the Twin Otter Wing

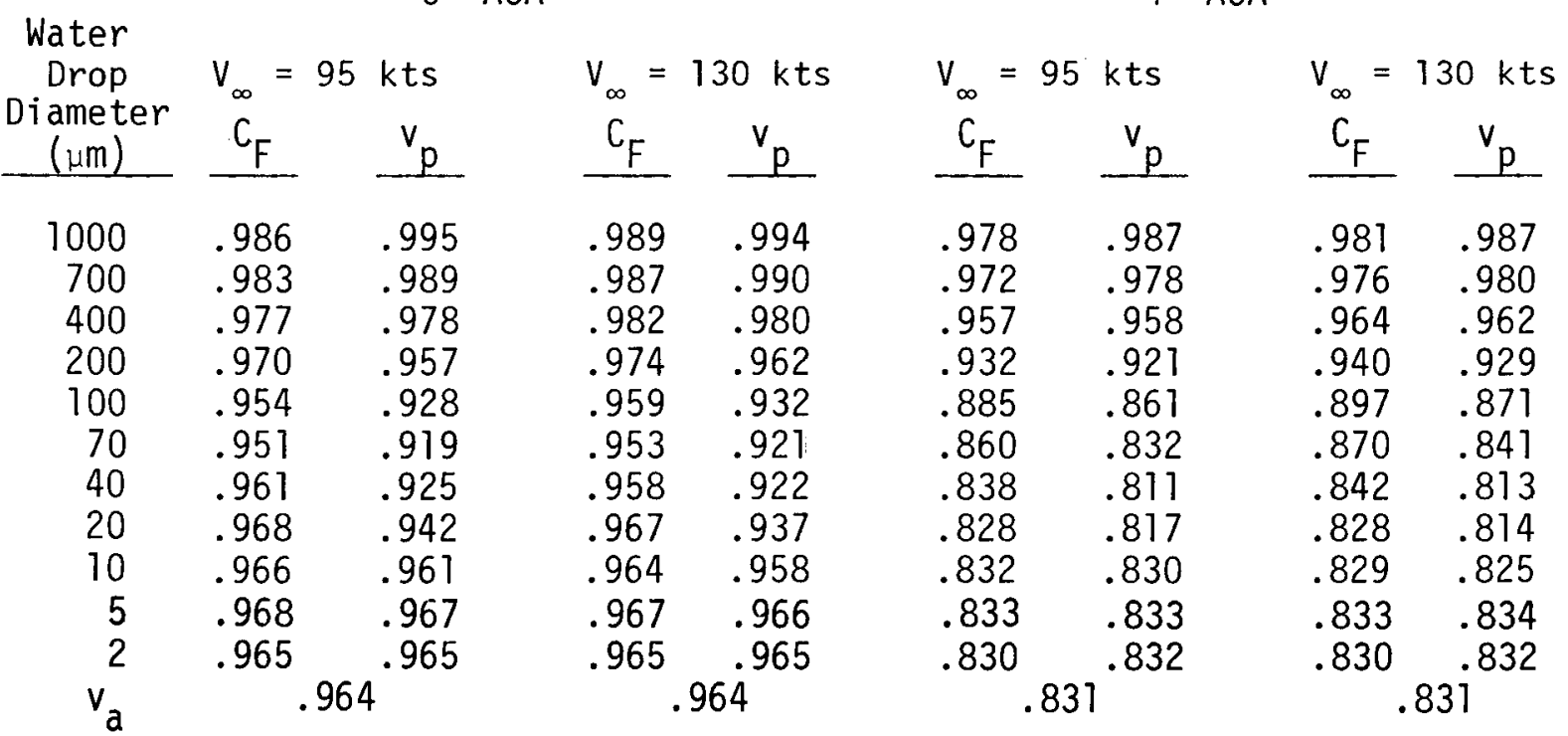


Isolated FSSP

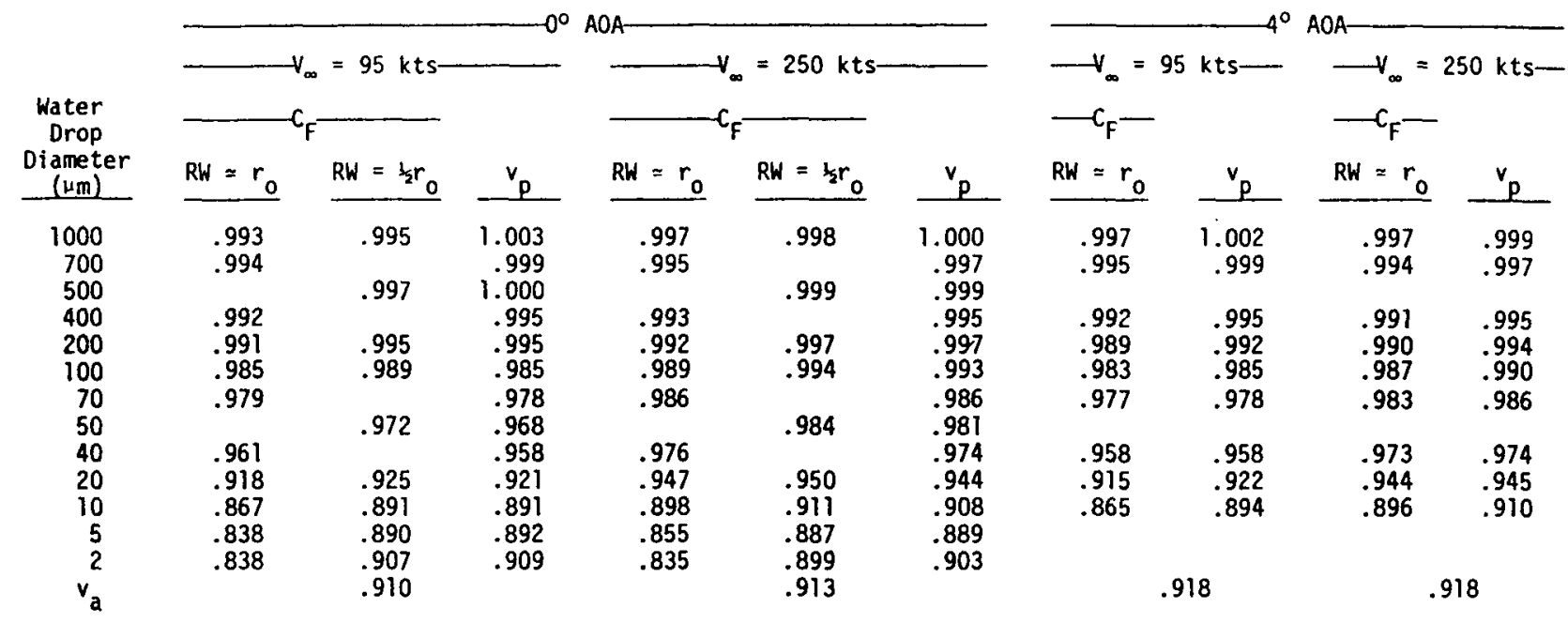

FSSP Mounted Under the Twin Otter Wing

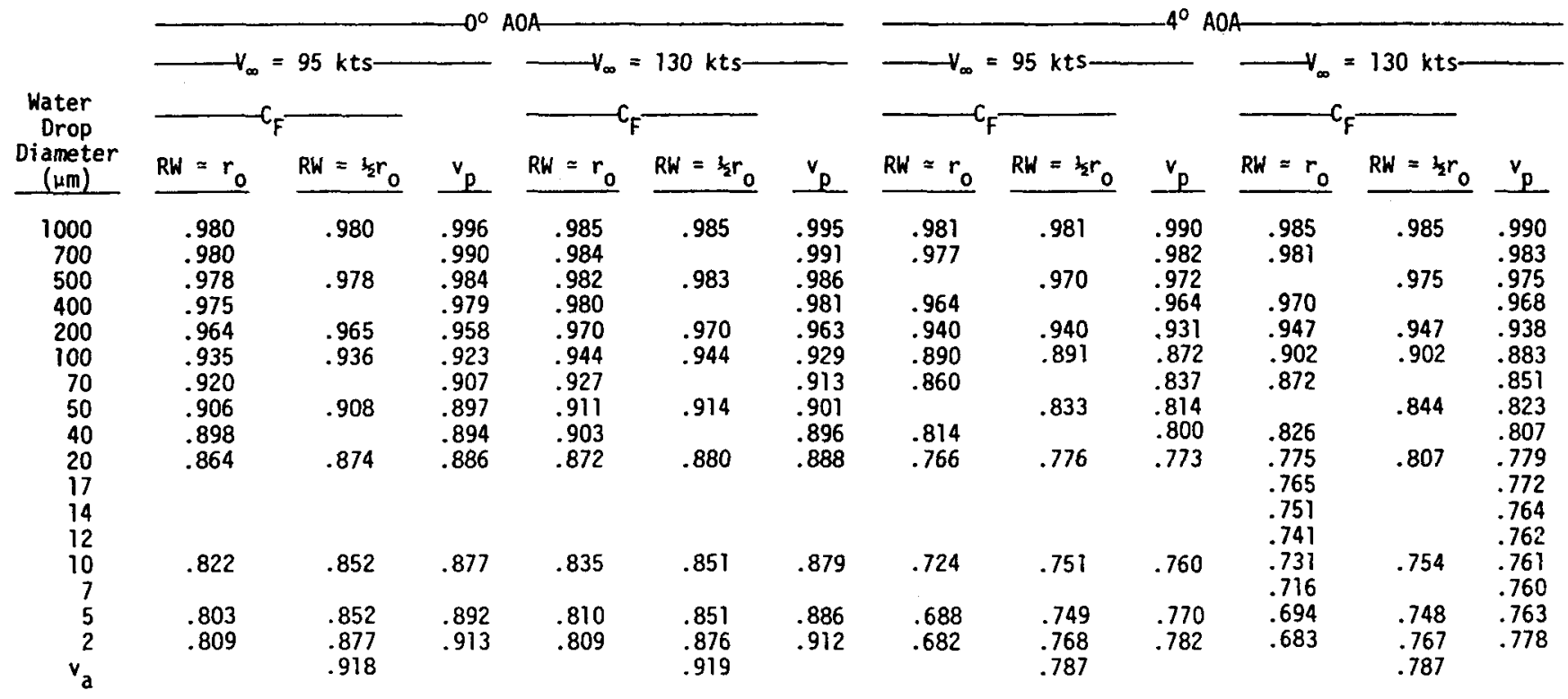


At Location of OAP Under the Twin Otter Wing No Instrument

\begin{tabular}{|c|c|c|c|c|c|c|c|c|}
\hline \multirow{3}{*}{$\begin{array}{c}\text { Water } \\
\text { Drop } \\
\text { Diameter } \\
(\mu \mathrm{m})\end{array}$} & \multicolumn{4}{|c|}{ no } & \multicolumn{4}{|l|}{ 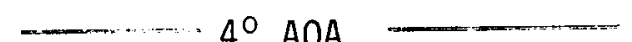 } \\
\hline & \multicolumn{2}{|c|}{$V_{\infty}=95 \mathrm{kts}$} & \multicolumn{2}{|c|}{$V_{\infty}=130 \mathrm{kts}$} & \multicolumn{2}{|c|}{$V_{\infty}=95 \mathrm{kts}$} & \multicolumn{2}{|c|}{$v_{\infty}=130 \mathrm{kts}$} \\
\hline & $C_{F}$ & $v_{p}$ & $\mathrm{C}_{\mathrm{F}}$ & $v_{p}$ & $\mathrm{C}_{\mathrm{F}}$ & $v_{p}$ & $C_{f}$ & $v_{p}$ \\
\hline 1000 & .987 & .996 & .990 & .996 & .980 & .990 & .983 & .990 \\
\hline 700 & .984 & .992 & .988 & .992 & .975 & .982 & .979 & .984 \\
\hline 400 & .981 & .983 & .985 & .985 & .963 & .966 & .969 & .970 \\
\hline 200 & .977 & .970 & .982 & .973 & .944 & .937 & .951 & .943 \\
\hline 100 & 973 & .954 & .975 & .956 & .911 & .892 & .920 & .900 \\
\hline 70 & 979 & .955 & .977 & .954 & .899 & .875 & .904 & .880 \\
\hline 40 & .999 & .974 & .995 & .969 & .898 & .872 & .896 & .870 \\
\hline 20 & 1.008 & .999 & 1.008 & 90 & .897 & .889 & .897 & .885 \\
\hline 10 & 1.009 & 1.007 & 1.009 & 1.006 & .899 & .898 & .899 & .897 \\
\hline 5 & 1.008 & 1.009 & & & .899 & .901 & & \\
\hline 2 & 1.009 & 1.009 & & & .899 & .902 & & \\
\hline$v_{a}$ & & & & 009 & 9 & & & \\
\hline
\end{tabular}

At Location of FSSP Under the Twin Otter Wing No Instrument

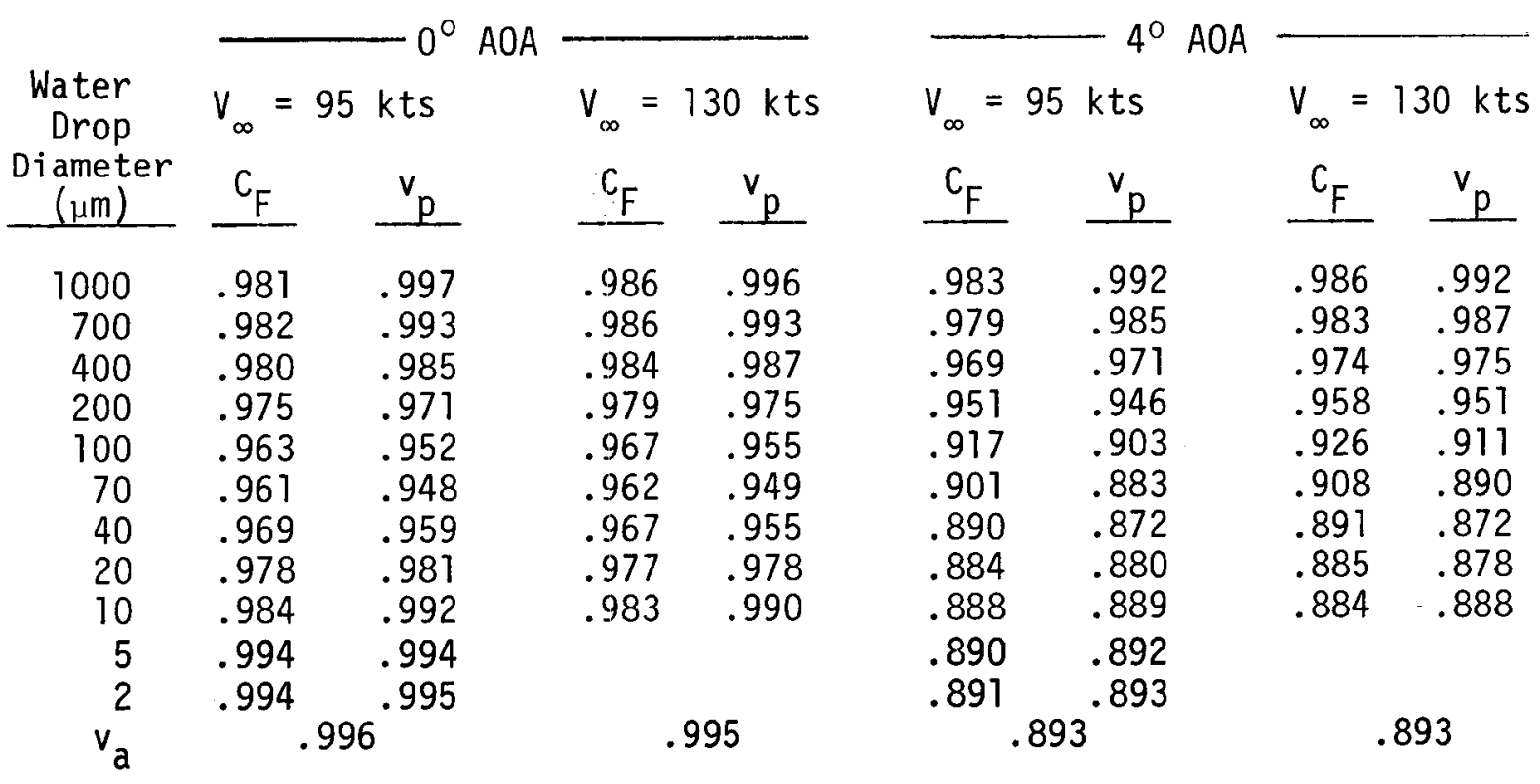




\section{APPENDIX B}

\section{DRAG VECTOR ANGLES}

The drag vector, $\vec{D}$, is given by the first term on the right side of eq. (1) (p. 18). Angle $\alpha$ is the angle between the projection of $\vec{D}$ in the $z=0$ plane (i.e., horizontal plane) and the $x$ axis vector, and $\beta$ is the angle $\vec{D}$ makes with the $z=0$ plane. The geometry is

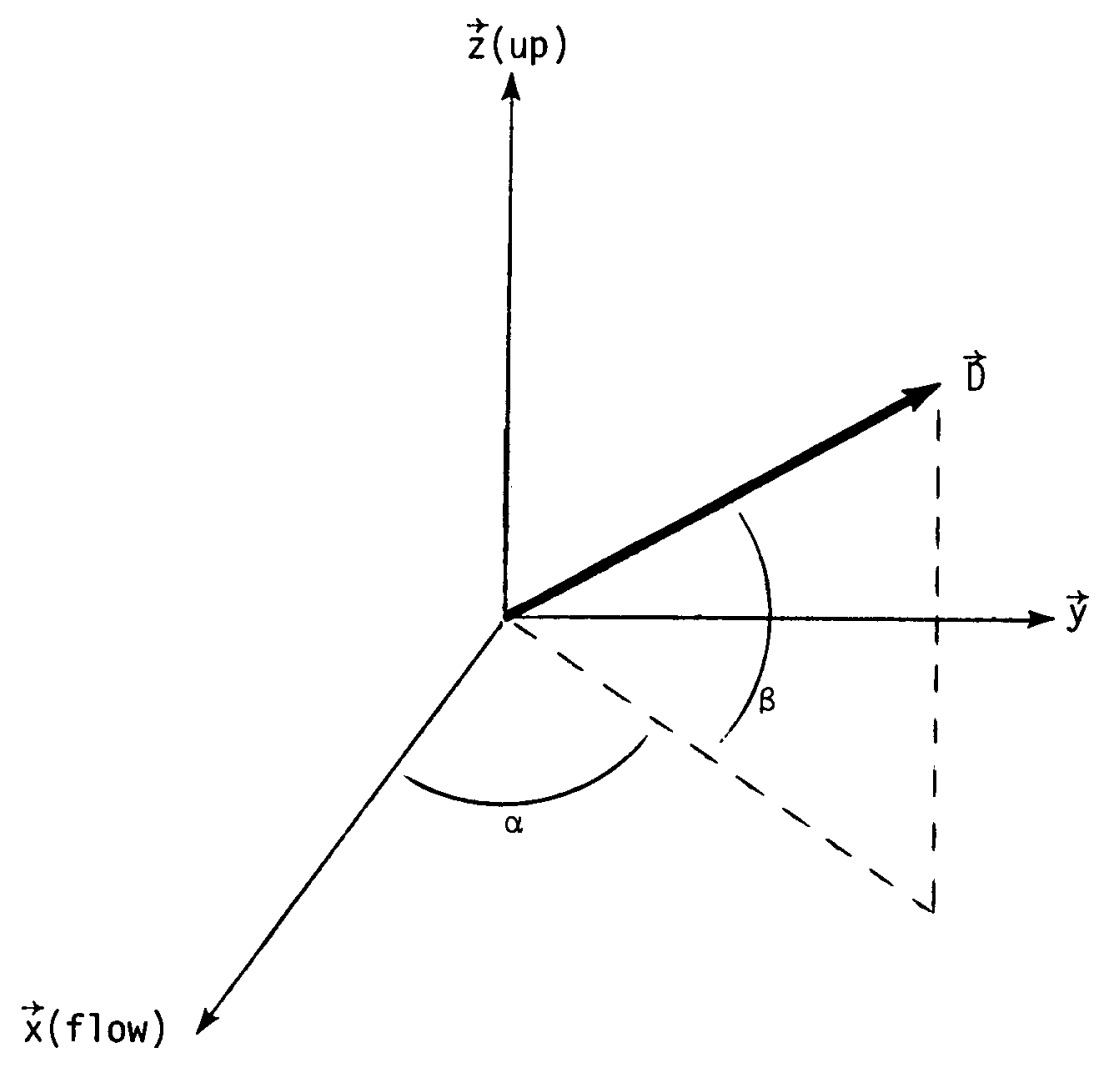

For the wing-mounted instruments we take the outboard direction (i.e., toward the wing tip) to be the direction of $\vec{y}$.

Tabulated drag vector angles (degrees) are for the final points of the central trajectories of flux tubes of water drops from the free stream to the instruments. For the OAP this point is close to the center of the laser beam, while for the FSSP it is close to the center of the measurement tube intake orifice. 
Isolated OAP

(angles in degrees)

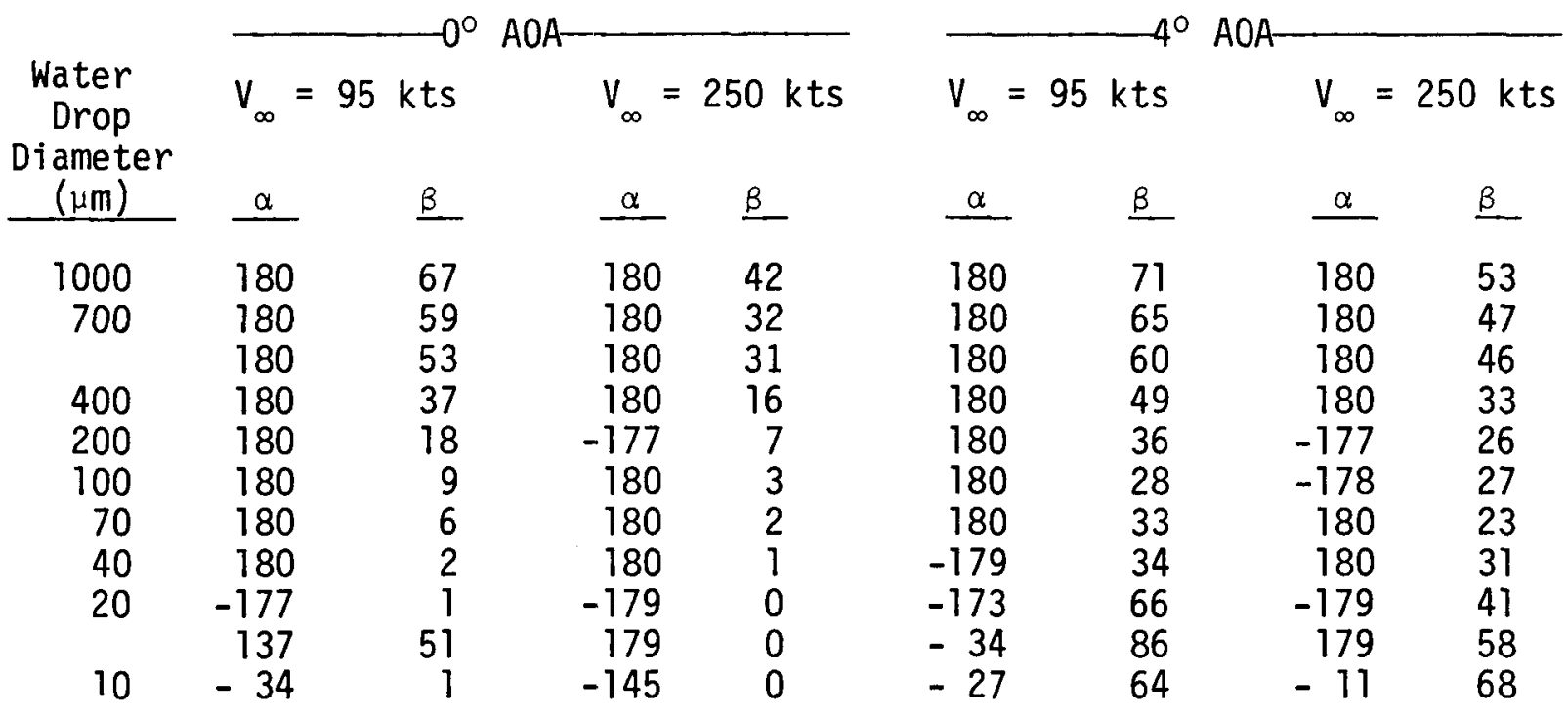

Isolated FSSP

(angles in degrees)

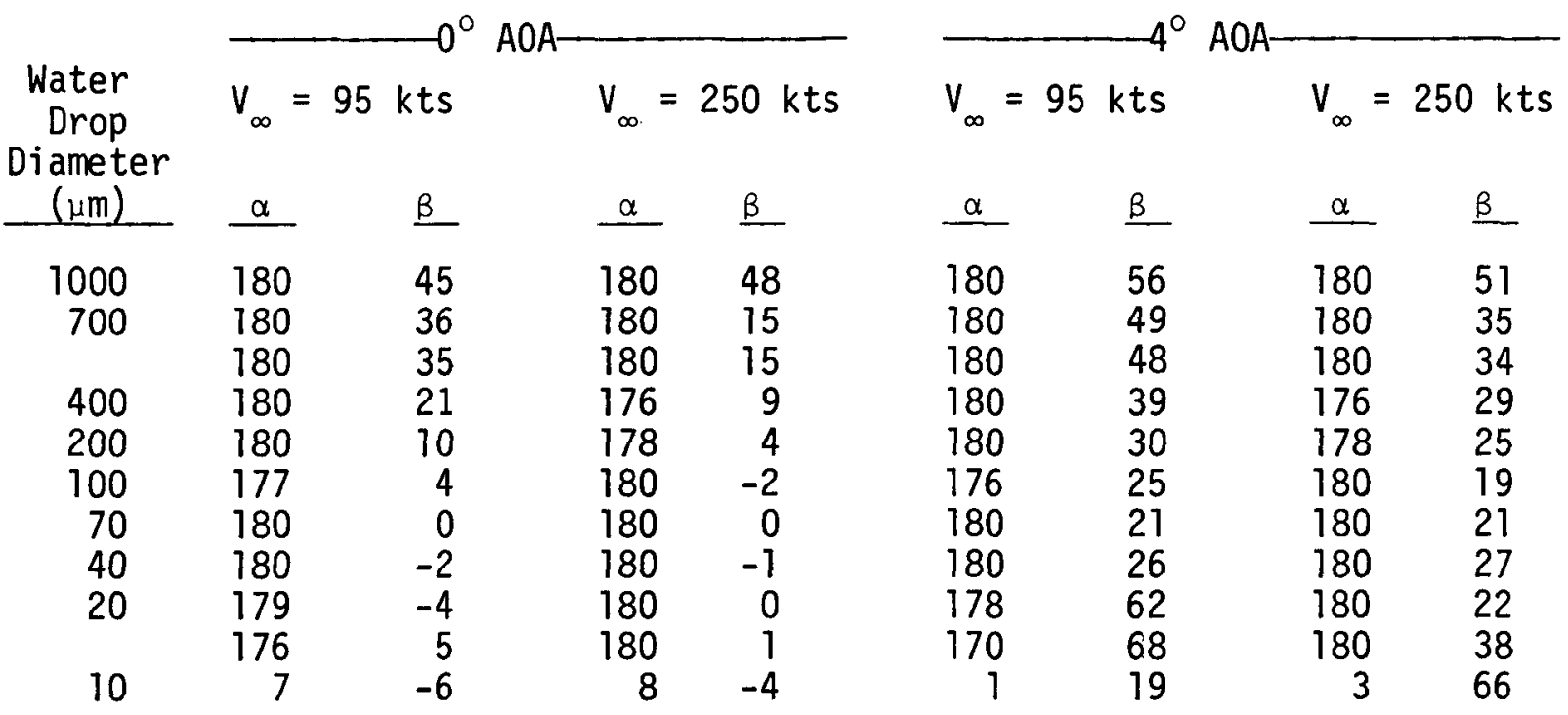


OAP Mounted Under the Twin Otter Wing (angles in degrees)

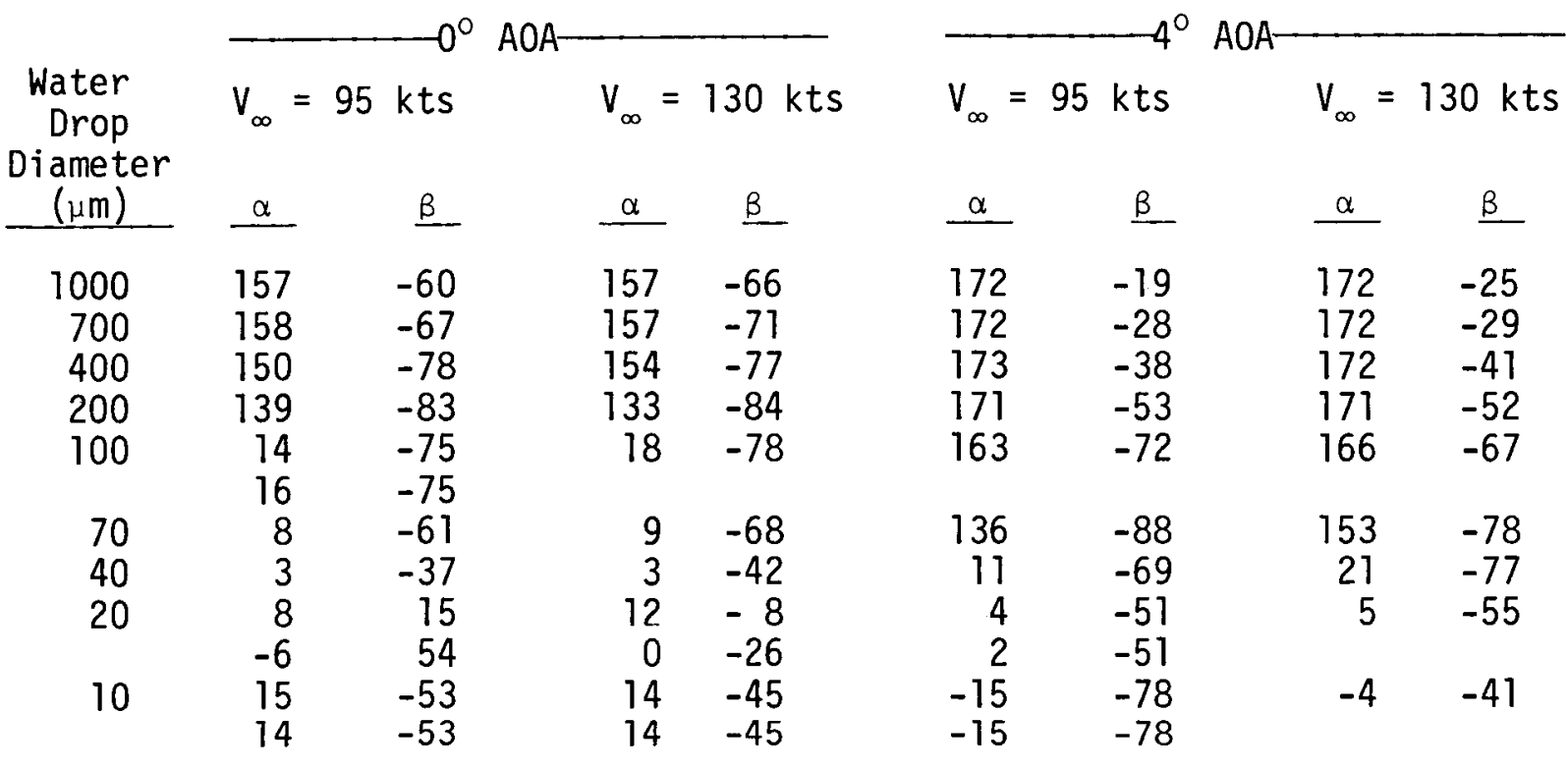

FSSP Mounted Under the Twin Otter Wing (angles in degrees)

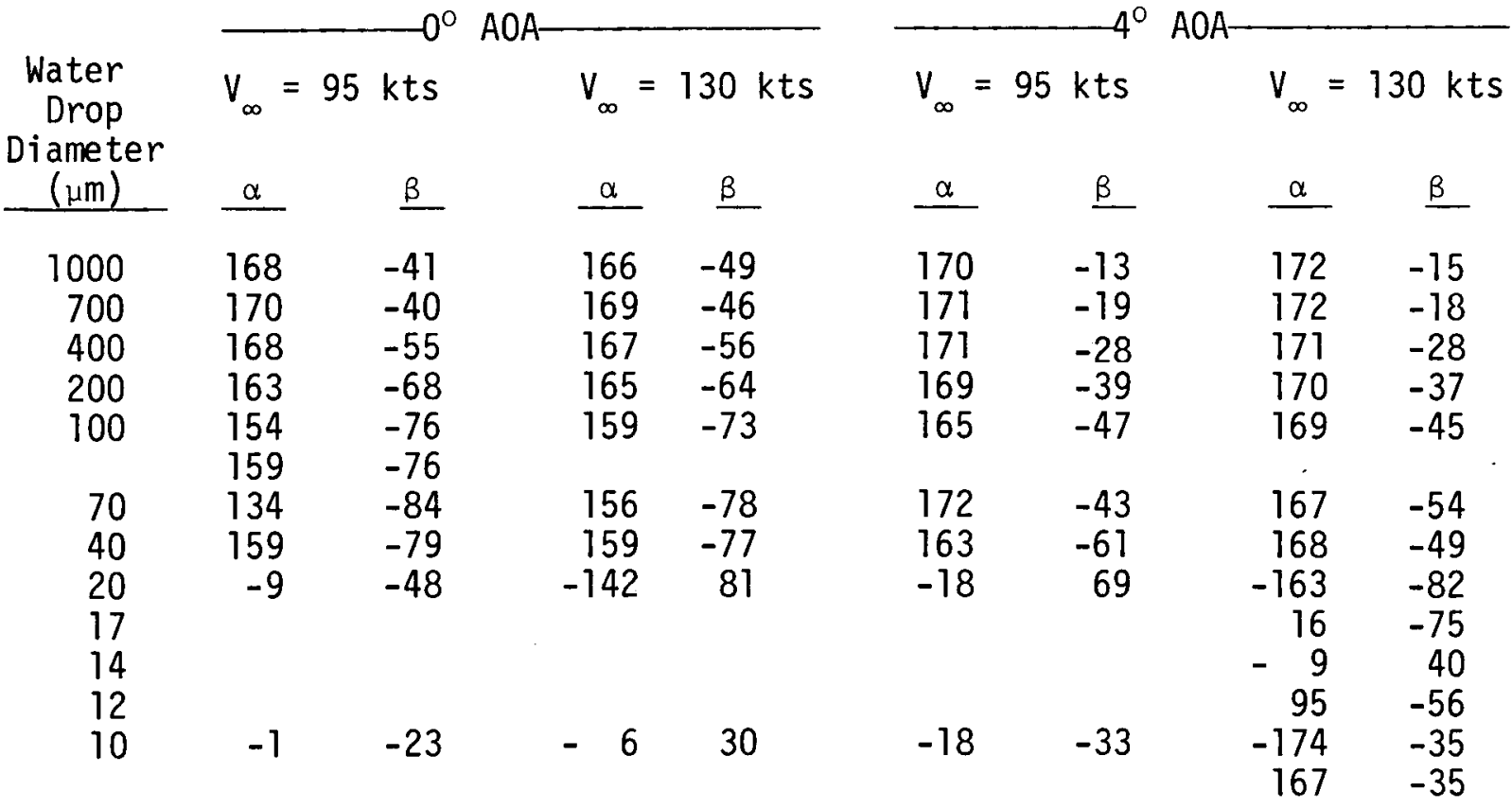




\section{REFERENCES}

1. Norment, H. G.: Effects of Airplane Flowfields on Hydrometeor Concentration Measurements, Preprints, International Conference on Cloud Physics, July 26-30, 1976, Boulder, Colorado, pp. 591-596.

2. Norment, H. G.: Three-Dimensional Airflow and Hydrometeor Trajectory Calculation With Applications, AIAA 23rd Aerospace Science Meeting, January 14-17, 1985, Reno, Nevada, Paper AIAA-85-0412.

3. Norment, H. G.: Calculation of Water Drop Trajectories To and About Arbitrary Three-Dimensional Lifting and Nonlifting Bodies in Potential Airflow, NASA Contractor Report 3935, October 1985.

4. Shaw, R. J., Norment, H. G. and Quealy, A.: The Use of a ThreeDimensional Water Drop Trajectory Analys is to Aid in Interpreting Icing Cloud Data, AIAA 24th Aerospace Sciences Meeting, January 1986, Reno, Nevada, Paper AIAA-86-0405.

5. Drummond, A. M. and MacPherson, J. I.: Theoretical and Measured Airflow About the Twin Otter Wing, NAE-AN-19, NRC No. 33184, March 1984.

6. Drummond, A. M.: Aircraft Flow Effects On Cloud Droplet Images and Concentrations, NAE-AN-21, NRC No. 23508, June 1984.

7. Knollenberg, R. G.: The Optical Array: An Alternative to Scattering or Extinction for Airborne Particle Size Determination, J. Appl. Meteor., Vol. 9, 1970, pp. 86-103.

8. Knollenberg, R. G.: Three New Instruments for Cloud Physics Measurements: The 2-D Spectrometer, the Forward Scattering Spectrometer Probe, and the Active Scattering Aerosol Spectrometer, Preprints, International Conference on Cloud Physics, July 26-30, 1976, Boulder, Colorado, pp. 554-561.

9. Hess, John L.: Calculation of Potential Flow About Arbitrary ThreeDimensional Lifting Bodies, Report No. MDC J5679-01, 0ct. 1972. AD-755 480 .

10. Hess, John L. and Smith, A.M.0.: Calculation of Non-Lifting Potential Flow About Arbitrary Three-Dimensional Bodies", Report E.S. 40622, March 15, 1962. AD-282 255. 
11. Hess, J. L. and Martin, R. P.: Improved Solution for Potential Flow About Arbitrary. Axisymmetric Bodies By Use of a Higher-Order Surface Source Method. Part I. Theory and Results, Douglas Aircraft Company, MDC J6627-01, NASA CR 134694, July 1974. N74-33791.

12. Friedman, D. M.: Improved Solution for Potential Flow About Arbitrary Axisymmetric Bodies By Use of a Higher Order Surface Method. Part II. User's Manual for Computer Program, Douglas Aircraft Company, MDC J6627-02, NASA CR 134695, Ju1y 1974. N74-33792.

13. Beard, K. V.: Terminal Velocity and Shape of Cloud and Precipitation Drops Aloft, J. Atm. Sci., Vol. 33, 1976, pp. 851-864.

14. Gunn, R. and Kinser, G. D.: The Terminal Velocity of Fall for Water Droplets in Stagnant Air, J. Meteor., Vol. 6, 1949, pp. 243-248.

15. Norment, H. G. and Zalosh, R. G.: Effects of Airplane Flowfields on Hydrometeor Concentration Measurements, AFCRL-TR-0602, Dec. 6, 1974. AD-A006 690.

16. Norment, H. G.: Calculation of Water Drop Trajectories To and About Arbitrary Three-Dimensional Bodies in Potential Airflow, NASA CR 3297 , Aug. 1980. N80-28302.

17. U.S. Standard Atmosphere, NOAA and NASA, NOAA-S/T76-1562, 1976.

18. Beard, K. V.: Reorientation of Hydrometeors in Aircraft Accelerated Flow, J. Climate and App1. Meteor., Vol. 22, No. 11, 1983, pp. 19611963. 


\begin{tabular}{|c|c|c|}
\hline \multicolumn{3}{|c|}{ Report Documentation Page } \\
\hline $\begin{array}{ll}\text { 1. Report No. } & \text { NASA CR }-4113 \\
& \text { DOT/FAA/CT-87130 }\end{array}$ & 2. Government Accession No. & 3. Recipient's Catalog No. \\
\hline \multirow{2}{*}{\multicolumn{2}{|c|}{$\begin{array}{l}\text { 4. Title and Subtitle } \\
\text { Three-Dimensional Trajectory Analyses of Two Drop } \\
\text { Sizing Instruments: PMS OAP and PMS FSSP }\end{array}$}} & $\begin{array}{l}\text { 5. Report Date } \\
\text { February } 1988\end{array}$ \\
\hline & & 6. Performing Organization Code \\
\hline \multicolumn{2}{|l|}{ 7. Author(s) } & 8. Performing Organization Report No. \\
\hline \multicolumn{2}{|l|}{ Hillyer G. Norment } & $(E-3851)$ \\
\hline & & 10. Work Unit No. \\
\hline \multicolumn{2}{|l|}{ 9. Performing Organization Name and Address } & $505-68-11$ \\
\hline \multirow{2}{*}{\multicolumn{2}{|c|}{$\begin{array}{l}\text { Atmospheric Science Associates } \\
186 \text { Peter Spring Road } \\
\text { Concord, MA } 01742\end{array}$}} & $\begin{array}{l}\text { 11. Contract or Grant No. } \\
\text { NAS3-24630 }\end{array}$ \\
\hline & & 13. Type of Report and Period Covered \\
\hline \multirow{2}{*}{\multicolumn{2}{|c|}{$\begin{array}{l}\text { 12. Sponsoring Agency Name and Address } \\
\text { National Aeronautics and Space Administration } \\
\text { Lewis Research Center } \\
\text { Cleveland, Ohio } 44135-3191\end{array}$}} & $\begin{array}{l}\text { Contractor Report } \\
\text { Final }\end{array}$ \\
\hline & & 14. Sponsoring Agency Code \\
\hline
\end{tabular}

15. Supplementary Notes

Project Managers, Robert J. Shaw, Propulsion Systems Division, NASA Lewis

Research Center, and James Riley, FAA Technical Center, Atlantic City,

New Jersey 08405.

16. Abstract

Flow-induced distortions of water drop fluxes and speeds seen by the instruments have been predicted by use of three-dimensional flow and trajectory calculation methods. Sensitivities have been determined, for the instruments in isolation and mounted under the wing of a DeHavilland Twin Otter airplane, to: water drop diameter $(2-1000 \mu \mathrm{m})$, angle of attack and free stream air speed. For the OAP in isolation and on the Twin Otter at $0^{\circ}$ angle of attack, flux distortions of practical consequence are not found. At $4^{\circ}$ airplane angle of attack, partial flow stagnation under the uptilted wing causes significant decrease in both flux and speed for cloud size droplets. For the FSSP in isolation, only marginally significant sensitivities to free stream air speed are found, and no sensitivity is found to angle of attack. For the wing-mounted instrument, substantial sensitivity is found to angle of attack. Both speed and flux of cloud-size droplets are predicted to be undermeasured by from $12-24 \%$ depending on airplane angle of attack. For the wing-mounted instruments, effects of flow about the instruments themselves are found to be equal in importance to effects of flow about the airplane. Preferred orientation (canting) angles of distorted water drops are found to be functions of drop size, angle of attack and air speed.

17. Key Words (Suggested by Author(s))

Aircraft icing; Water drop sizing instruments; Aircraft-mounted instruments; PMS OAP; PMS FSSP; Water drop trajectories; Three-dimensional potential flow; Trajectory analyses; Water drop 18. Distribution Statement fluxes; Preferred orientation

Unclassified - Unlimited Subject Category 03
19. Security Classif. (of this report) Unclassified
20. Security Classif. (of this page) Unclassified
21. No of pages

63
22. Price* A04 
Report No. DOT/FAA/CT-87130

NASA Contractor Report 4113

THREE-DIMENSIONAL TRAJECTORY

ANALYSES OF TWO DROP SIZING

INSTRUMENTS: PMS OAP

AND PMS FSSP

Hillyer G. Norment

Atmospheric Sclence Associates

Concord, Massachusetts

FINAL REPORT

CONTRACT NAS3-24630

FEBRUARY 1988

National Aeronautics and Space Administration

Lewis Research Center, Cleveland, Oh1o

Department of Transportation

Federal Aviation Administration Technical Center

Atlantic C1ty International A1rport, NJ 08405

Front Cover, Inside Cover, and Report Documentation Page:

Change Report No. DOT/FAA/CT-87130 to DOT/FAA/CT-87/30.

This document is avallable to the public through the National Technical Information Service, Springfield, Virginia 22161

Include Disclaimer Statement (attached).

Released May 1988 
NOTICE

Th1s document 18 disseminated under the oponsorship of the U. S. Department of Transportation in the 1nterest of Information exchange. The Unfted States Government assumes no liablilty for the contents or use thereof.

The Unfted States Government does not endorse products or manufacturers. Trade or manufacturers' names appear herein solely because they are considered essential to the objective of this report. 